\title{
Research Progresses and Challenges of Flexible Zinc Battery
}

\author{
Yunfei Xu, Xin Xu, Mei Guo, Guoxin Zhang * and Yaqun Wang * \\ Department of Energy Storage Technology, Shandong University of Science and Technology, Qingdao, China
}

Flexible zinc batteries have great potential in wearable electronic devices due to their high safety, low cost, and environmental friendliness. In the past few years, a great deal of work on flexible zinc batteries has been reported, with exciting results. Therefore, many solutions have been proposed in electrode design and electrolyte preparation to ensure the desired flexibility without sacrificing the capacity. This paper reviews the recent progress of flexible zinc batteries. We discuss the differences between various anode materials, cathode materials, and electrolytes, introduce the differences of electrode preparation methods of active materials on flexible substrates and their influence on the performance of the battery. Finally, the challenges and future research trends of flexible zinc batteries in capacity and mechanical properties are pointed out.

\section{OPEN ACCESS}

Edited by: Yu Ding,

University of Maryland, United States

Reviewed by:

Kangning Zhao,

Swiss Federal Institute of Technology Lausanne, Switzerland Yumin Qian,

Beijing Institute of Technology, China

${ }^{*}$ Correspondence: Guoxin Zhang zhanggx@sdust.edu.cn Yaqun Wang yqwang@sdust.edu.cn

Specialty section: This article was submitted to Electrochemistry, a section of the journal Frontiers in Chemistry

Received: 02 December 2021 Accepted: 25 January 2022 Published: 14 February 2022

Citation:

Xu Y, Xu X, Guo M, Zhang G and Wang $Y$ (2022) Research Progresses and Challenges of Flexible Zinc Battery.

Front. Chem. 10:827563.

doi: 10.3389/fchem.2022.827563
Keywords: flexible, zinc ion battery, zinc-air battery, mechanical property, flexible substrate, in situ growth, inkjet printing, screen printing

\section{INTRODUCTION}

With the development of miniaturization of electronic chips, it is possible to integrate electric devices, such as implantable medical devices, wearable health monitoring systems, flexible displays, and intelligent clothing, which have attracted the attention of researchers all over the world. (Yu et al., 2017; Liu et al., 2018; Sumboja et al., 2018; Zhang et al., 2018; Dong et al., 2021).As an indispensable part of the flexible electronic equipment, the battery needs to have good cycling and safety performance to meet the requirements. Especially when the flexible battery follows the deformation of the flexible electronic devices, the mechanical and electrochemical properties are required to be higher.

As an electrode material, zinc has the advantages of lower cost, more content in the crust and lower redox equilibrium potential than lithium. Moreover, using environmentally insensitive zinc makes zinc-based batteries manufacture easier and package cheaper than lithium-based batteries. (Fang et al., 2018). At present, conventional zinc-based batteries such as $\mathrm{Zn}-\mathrm{MnO}_{2}, \mathrm{Zn}-\mathrm{Ni}$ and $\mathrm{Zn}$-Air have already been commercialized, but they are mainly rigid and used in non-flexible electronic devices. Many researches have been done to make these batteries flexible. In addition, Zinc ion batteries (ZIBs) because of its high energy density, low cost, environmental friendliness, safety and other advantages are gradually coming into people's horizons, have good prospects in portable devices. ZIB, as a promising alternative to lithium ion battery, has attracted widespread attention. (Tan et al., 2017; Li et al., 2019a; Yu et al., 2019; Zhang et al., 2020a).

At present, great progresses have been made in electrode materials selection, flexible electrode preparation and electrolyte design of flexible zinc ion batteries. (Li et al., 2019a). In this review, the latest research progresses in electrode materials, electrolytes, and adhesion methods of active material are reviewed. Lastly, some concluding remarks were prospected to outline the challenges and future research trends for flexible zinc batteries. 
A

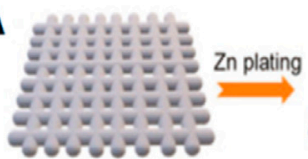

CC

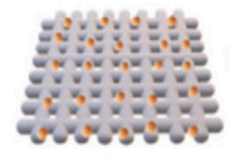

AgNPs@CC

Zn plating

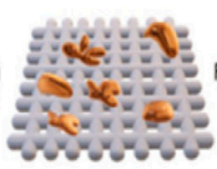

$x<y=0$
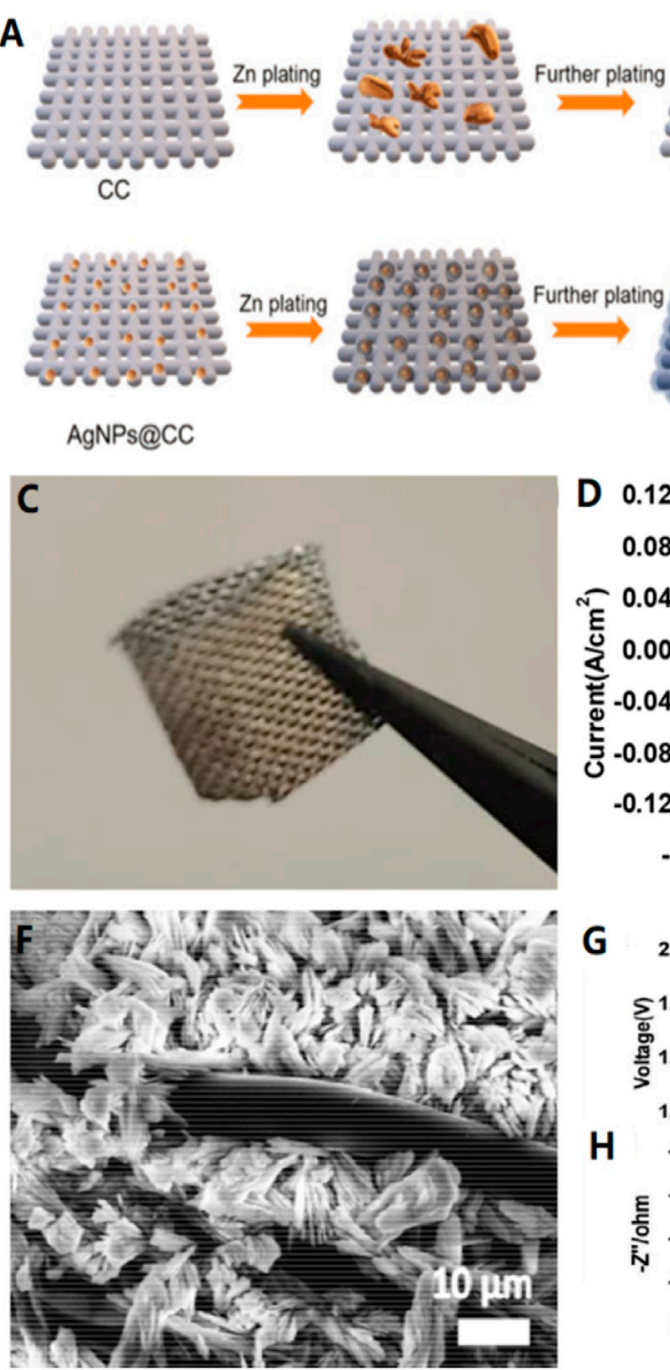

G

H

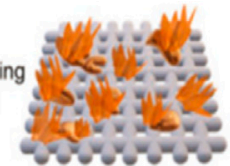

$\mathrm{CC} / \mathrm{Zn}$

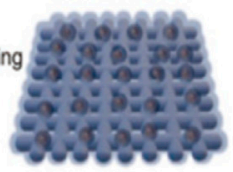

AgNPs@CC/Zn
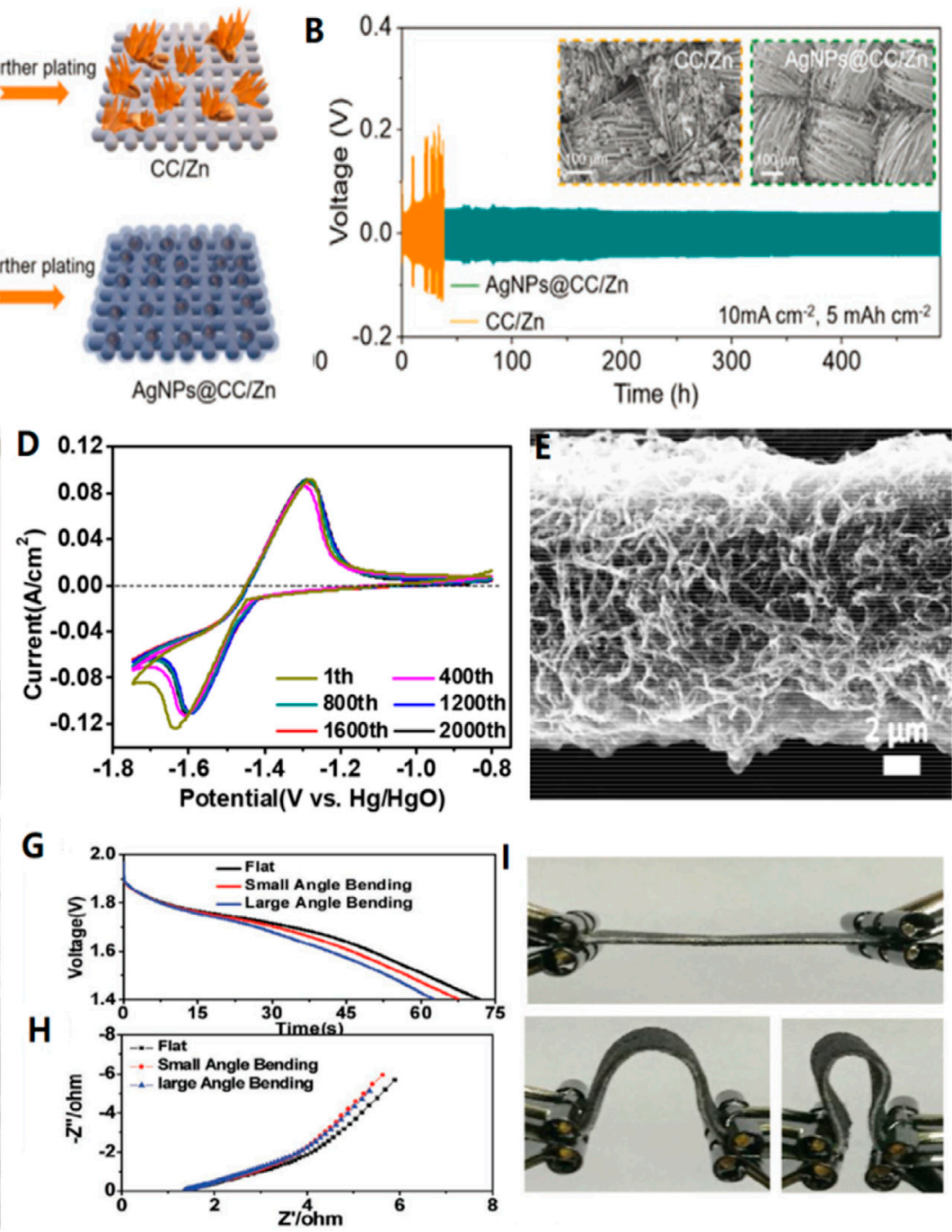

FIGURE 1 | (A) Schematic diagram of Zn deposition on bare CC and AgNPs@CC scaffolds. (B) The capacity is 5 mA h/cm² at $10 \mathrm{~mA} \mathrm{h/cm²} \mathrm{current} \mathrm{density.} \mathrm{Inset:}$ SEM images of CC/Zn and AgNPs@CC/Zn electrodes after circulation. (C) Flexible AgNPs@CC/Zn electrode under bending.Copyright 2021 Wiley-VCH GmbH. (D) CV curves of the CC-CF@120ZnO at different cycles. SEM images of (E) CC-CF@ZnO and (F) CC-ZnO after cycling test, showing the importance of CFs for preventing the Zn dendrite growth. (G-I) Discharge curves and EIS results of solid-state batteries under different bending conditions. Copyright 2016 WILEY-VCH Verlag GmbH \& Co. KGaA, Weinheim.

\section{COMMON MATERIALS FOR FLEXIBLE ZINC BATTERIES}

\section{Anode Materials}

Zinc metal anodes are of particular interest to the flexible battery market due to their low material cost, high theoretical capacity $\left(820 \mathrm{~mA} \mathrm{~h} / \mathrm{g}, 5,854 \mathrm{~mA} \mathrm{~h} / \mathrm{cm}^{3}\right.$ ), (Kaveevivitchai and Manthiram, 2016), good rechargeability and safe chemistry. The most common anode in flexible zinc ion battery is zinc foil, because of its good mechanical properties. However, the stiffness of heavy metal zinc foil anodes reduces the energy density, making it impossible to apply to industrial flexible, wearable energy storage systems. (Pan et al., 2016). In addition, the main challenges faced by zinc metal anodes are the mechanical stability of the electrode during long- term deformation and uncontrollable dendrite growth during cycling, resulting in poor cycle performance and coulomb efficiency of the battery, which severely limits the service life of flexible zinc ion batteries and hinders their practical application. (Lao-atiman et al., 2017; Han et al., 2018a; Li et al., 2018a; Ma et al., 2018; Tang et al., 2019; Zeng et al., 2019; Li et al., 2020a; Nguyen et al., 2020). In order to solve these problems of $\mathrm{Zn}$ anode, there are several strategies, including:

a) Method for constructing composite zinc anode.

Chen and his colleagues proposed a heterogeneous metal seedmediated strategy. (Chen et al., 2021a). The basic idea is through the inkjet printing on the main chain of the three dimensional 
conductive printing silver nanoparticles, in order to induce the homogeneous nucleation of zinc, and avoid initial electroplating phase of the dendrite growth. Therefore, AgNPs@CC/Zn anode has excellent performance at a high current density of $10 \mathrm{~mA} /$ $\mathrm{cm}^{2}$, with cycle performance exceeding $480 \mathrm{~h}$. (Figures 1A,B)

b) Deposition of zinc materials on a highly conductive substrate.

Zinc oxide nanoparticles are deposited on a three-dimensional layered carbon cloth-carbon nanofiber (CC-CF) substrate as an anode (CC-CF@ZnO). (Figures 1D,E) The device exhibits excellent stability, maintaining up to $91.45 \%$ initial capacity after 1,000 cycles and $72.90 \%$ initial capacity after 2,400 cycles. The significant increase in cyclic capacity is due to the uniform deposition of nano particles on the three-dimensional highly conductive nano-carbon fibers, which alleviates the shape change during the electrochemical reaction. In particular, it avoids the uneven distribution of current and zinc deposition, thus preventing the formation of zinc dendrite. (Liu et al., 2016).

Pang (Guo et al., 2021) prepared zinc nanosheets/CC (Zn/CC) by electrodeposition, and $\mathrm{Zn}$ nanosheets were uniformly deposited on the surface of CC fiber. Form a threedimensional network interconnected with recent nano piece, insert for the ion-extraction process provides a rich active site. Compared with the same amount of conventional metal zinc anode foil, nanostructures zinc and CC skeleton integration enhances the flexibility of the anode, the formation of the surface of the more active, which helps the development of high performance flexible device.

\section{c) Coating inert material on zinc anode.}

For example, (Alfaruqi et al., 2018), constructed a Sn-doped $\mathrm{NaTi}_{2}\left(\mathrm{PO}_{4}\right)_{3}(\mathrm{NTP} / \mathrm{Sn})$ protective layer on the surface of zinc anode (Zn@NTP/Sn) to improve the cyclic stability of zinc anode. Using Sn doping $\mathrm{NaTi}_{2}\left(\mathrm{PO}_{4}\right)_{3}$ through the structure design and high performance of zinc anode interface features, is helpful to accelerate the transfer of $\mathrm{Zn}^{2+}$, increase the interface performance. At the current density of $0.4 \mathrm{~mA} / \mathrm{cm}^{2}$, the average voltage lag of $\mathrm{Zn@NTP/Sn} \mathrm{symmetric} \mathrm{cells} \mathrm{is} \mathrm{only}$ $17.4 \mathrm{mV}$, which is much lower than that of exposed $\mathrm{Zn}$ symmetric cells $(75.8 \mathrm{mV})$ and Zn@NTP symmetric cells $(43.7 \mathrm{mV})$. In addition, it has been reported that the zinc electrode surface was coated with $\mathrm{Al}_{2} \mathrm{O}_{3}$ coating (Lee et al., 2013) and $\mathrm{Bi}$ alloying (Jo et al., 2017) to improve HER overpotential and reduce self-discharge caused by hydrogen release, thus improving the cycle performance of the battery.

\section{d) Use appropriate electrolytes.}

For example, ionic liquid based zinc salt electrolyte is an effective way to solve the hydrogen evolution reaction (HER) and zinc dendrite growth of zinc ion batteries. (Ma et al., 2020) developed polyvinylidene fluoride hexafluoropropylene (PVDFHFP) $+5 \%$ poly (ethylene oxide) (PEO)+ILZE electrolyte (1-ethyl3-methylimidazolium tetrafluoroboric acid ([EMIM]BF $\left.{ }_{4}\right)$ ionic liquid) using $2 \mathrm{M}$ zinc tetrafluoroborate $\left(\mathrm{Zn}\left(\mathrm{BF}_{4}\right)_{2}\right)$ as carrier.
The final product is represented as PHP-ILZE. The electrolyte developed can achieve hydrogen-free, dendrite-free galvanizing/ stripping in $1,500 \mathrm{~h}(3,000$ cycles $)$ at $2 \mathrm{~mA} / \mathrm{cm}^{2}$ with a Coulomb efficiency of nearly $100 \%$. At the same time, oxygen-induced corrosion and passivation were effectively inhibited. This is the first demonstration of an all-solid-state zinc-ion battery based on a newly developed electrolyte, which simultaneously solves the problems of deep hydrogen evolution and dendrite growth of conventional zinc-ion batteries.

$\mathrm{Li}$ and his colleagues have developed a polyethylene glycol 600 (PEG 600) and polysorbate 20 (Tween 20) compound additive, as the organic inhibitors in alkaline electrolyte, mainly by inhibiting the hydrogen evolution reaction to a certain extent, inhibit the corrosion of zinc. Because Tween 20 is more polar than PEG 600, it absorbs zinc better. Because of Tween 20 highly branched structure, zinc cannot be Tween 20 complete coverage, and linear polyethylene glycol (peg) can be adsorbed on the rest of the active site, thus two kind of corrosion inhibitor for zinc corrosion synergy effect, the corrosion of the composite inhibitor is better than single corrosion inhibitor. (Liang et al., 2011).

The combination of these methods enables advanced flexible zinc anodes to be better designed with less dendrite growth, higher corrosion and passivation resistance, and less hydrogen evolution, suitable for quasi-solid zinc-based aqueous batteries.

\section{Cathode Materials}

The cathode materials commonly used in flexible zinc ion battery include various transition metal compounds, such as manganese (Qiu et al., 2017; Huang et al., 2019; Zu et al., 2019; Zhang et al., 2020b; Zhang et al., 2020c), cobalt, nickel (Liu et al., 2016; Wan et al., 2018) or molybdenum-based oxides/sulfides, Prussian blue analogues and conducting polymers (Eftekhari et al., 2017; Yao et al., 2020; Cong et al., 2021). (Table 1) Here, we will focus on the last 5 years of research.

\section{Manganese Based Materials}

Manganese based compounds have been widely used as cathode materials for ZIB due to their advantages of abundant resources, low cost and non-toxicity. (Pan et al., 2016; Zhang et al., 2016). $\mathrm{MnO}_{2}$ is considered as the most promising cathode material among many manganese based compounds. $\mathrm{MnO}_{2}$ is a material with a polymorphic crystal shape. Under different preparation conditions, the crystal shape, morphology, particle size, porosity, specific surface area are different, and then show different capacity and charge-discharge characteristics. (Xu et al., 2012; Alfaruqi et al., 2018). Huang and his colleagues have provided new insights into the energy storage mechanism of Waterborne zinc-manganese battery with the participation of $\mathrm{Mn}^{2+}$. (Huang et al., 2019). In the first discharge process, the combination of $\mathrm{Zn}^{2+}$ and $\mathrm{H}^{+}$insert promoted the $\mathrm{MnO}_{2}$ to $\mathrm{Zn}_{\mathrm{x}} \mathrm{MnO}_{4}, \mathrm{MnOOH}$ and $\mathrm{Mn}_{2} \mathrm{O}_{3}$ transformation, at the same time, raised the $\mathrm{pH}$ of the electrolyte, formation of $\mathrm{ZnSO}_{4} \cdot 3 \mathrm{Zn}(\mathrm{OH})_{2} \cdot 5 \mathrm{H}_{2} \mathrm{O}$ (noted as "BZSP"). Later in the charging process, $\mathrm{Zn}_{\mathrm{x}} \mathrm{MnO}_{4}, \mathrm{MnOOH}$ and $\mathrm{Mn}_{2} \mathrm{O}_{3}$ by extracting $\mathrm{Zn}^{2+}$ and $\mathrm{H}^{+}$reduction for alpha $\mathrm{MnO}_{2}, \mathrm{BZSP}$ and $\mathrm{Mn}^{2+}$ reacts $\mathrm{ZnMn}_{3} \mathrm{O}_{7} \cdot 3 \mathrm{H}_{2} \mathrm{O}$. Besides the electrochemical reaction, $\mathrm{Zn}^{2+}$ can also be in alpha $\mathrm{MnO}_{2}$, $\mathrm{ZnxMnO}_{4}$ and $\mathrm{ZnMn}_{3} \mathrm{O}_{7} \cdot 3 \mathrm{H}_{2} \mathrm{O}$ in the reversible insert and 
TABLE 1 | Comparison of electrochemical properties of different cathode materials.

\begin{tabular}{|c|c|c|c|c|c|c|}
\hline $\begin{array}{l}\text { Cathode } \\
\text { materials }\end{array}$ & Electrolyte & Capacity & Cycling stability & $\begin{array}{l}\text { Power } \\
\text { density }\end{array}$ & Energy density & References \\
\hline CC-CF@NiO & $\mathrm{PVA}+\mathrm{ZnO}+\mathrm{KOH}$ & $0.39 \mathrm{mAh} \mathrm{cm}^{-2}$ at $5 \mathrm{~mA} \mathrm{~cm}{ }^{-2}$ & $\begin{array}{l}91.45 \% \text { after } \\
1,000 \text { cycles }\end{array}$ & $57.5 \mathrm{~W} \mathrm{~kg}^{-1}$ & 19.7 Wh kg $\mathrm{Wg}^{-1}$ & Liu et al. (2016) \\
\hline $\mathrm{N}-\mathrm{CC} @ \mathrm{MnO}_{2}$ & $(\mathrm{PVA})+\mathrm{LiCl}+\mathrm{ZnCl}_{2}+\mathrm{MnSO}_{4}$ & $353 \mathrm{~mA} \mathrm{~h} \mathrm{~g}^{-1}$ at $0.5 \mathrm{~A} \mathrm{~g}^{-1}$ & $\begin{array}{l}93.6 \% \text { after } 1,000 \\
\text { cycles }\end{array}$ & $7.9 \mathrm{~kW} \mathrm{~kg}^{-1}$ & $440 \mathrm{~W} \mathrm{~h} \mathrm{~kg}^{-1}$ & Zu et al. (2019) \\
\hline $\mathrm{Ag}_{2} \mathrm{O}$ & $\mathrm{KOH}+\mathrm{LiOH}+$ polyacrylic acid & $3.78 \mathrm{~mA} \mathrm{~h} \mathrm{~cm}^{-2}$ & & & & $\begin{array}{l}\text { Eftekhari et al. } \\
(2017)\end{array}$ \\
\hline $\mathrm{AgO}$ & $\mathrm{KOH}+\mathrm{PVA}+\mathrm{Ca}(\mathrm{OH})_{2}$ & $>54 \mathrm{mAh} \mathrm{cm}^{-2}$ & & & & $\begin{array}{l}\text { Cong et al. } \\
(2021)\end{array}$ \\
\hline CC-PANI-FeCN & $\mathrm{ZnSO}_{4}+\mathrm{PVA}$ & $238 \mathrm{mAh} / \mathrm{g}$ at $0.2 \mathrm{~A} / \mathrm{g}$ & $\begin{array}{c}71 \% \text { at } 1,000 \\
\text { cycles }\end{array}$ & & & $\begin{array}{l}\text { Zhang et al. } \\
(2015)\end{array}$ \\
\hline $\mathrm{ZnHCF} @ \mathrm{MnO}_{2}$ & $\mathrm{ZnSO}_{4}+\mathrm{PVA}$ & $89 \mathrm{~mA} \mathrm{~h} / \mathrm{g}$ at $100 \mathrm{~mA} / \mathrm{g}$ & $\begin{array}{l}\sim 71 \% \text { at } 500 \\
\text { cycles }\end{array}$ & & & $\begin{array}{l}\text { Wang et al. } \\
(2017)\end{array}$ \\
\hline $\mathrm{CoFe}(\mathrm{CN}) 6$ & 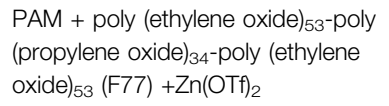 & $173.4 \mathrm{mAh} \mathrm{g}^{-1}$ at $0.3 \mathrm{~A} / \mathrm{g}$ & $\begin{array}{l}\text { 93.4\% after } 2000 \\
\text { cycles }\end{array}$ & & & $\begin{array}{l}\text { Javed et al. } \\
\text { (2020) }\end{array}$ \\
\hline AgNPs@CC & $\mathrm{Zn}\left(\mathrm{CF}_{3} \mathrm{SO}_{3}\right)_{2}$ & $255 \mathrm{mAh} / \mathrm{g}$ at $5.0 \mathrm{~mA} / \mathrm{g}$ & $\begin{array}{l}184 \mathrm{mAh} / \mathrm{g} \text { at } \\
1,200 \text { cycles }\end{array}$ & & & $\begin{array}{l}\text { Chen et al. } \\
\text { (2021a) }\end{array}$ \\
\hline P-MnO2-x@VMG & $\mathrm{PVA}+\mathrm{ZnCl}_{2}+\mathrm{MnSO}_{4}$ & $284.2 \mathrm{~mA} \mathrm{~h} / \mathrm{g}$ at $0.5 \mathrm{~A} / \mathrm{g}$ & $\begin{array}{c}>87 \% \text { at } 500 \\
\text { cycles }\end{array}$ & & $369.5 \mathrm{Wh} \mathrm{kg}^{-1}$ & $\begin{array}{l}\text { Chamoun et al. } \\
\text { (2018) }\end{array}$ \\
\hline t-CNTs-PA-PE & $\mathrm{ZnSO}_{4}+\mathrm{PAM}$ & $238 \mathrm{~mA} \mathrm{~h} / \mathrm{g}$ at $0.2 \mathrm{~A} / \mathrm{g}$ & $\begin{array}{c}\sim 100 \% \text { at } 1,500 \\
\text { cycles }\end{array}$ & & & Jia et al. (2015) \\
\hline $\begin{array}{l}\text { CC-MOF derived } \\
\text { Ag nanowires }\end{array}$ & $\mathrm{KOH}+\mathrm{PVA}$ & $1.605 \mathrm{~mA} \mathrm{~h} / \mathrm{cm}^{2}$ at & $\begin{array}{l}\text { CC-MOF derived } \\
\text { Ag nanowires }\end{array}$ & $2.8 \mathrm{~mW} / \mathrm{cm}^{2}$ & $1.87 \mathrm{mWh} / \mathrm{cm}^{2}$ & $\begin{array}{l}\text { Tehrani et al. } \\
(2015)\end{array}$ \\
\hline $\mathrm{MnO}_{2}$ & $\mathrm{ZnSO}_{4}+\mathrm{MnSO}_{4}$ & $\begin{array}{l}19.3 \mathrm{mAh} / \mathrm{cm} 3 \\
\text { (corresponding to } 393 \mathrm{~mA} \mathrm{~h} / \\
\text { g) at } 7.5 \mathrm{~mA} / \mathrm{cm}^{3}\end{array}$ & $\begin{array}{c}83.9 \% \text { at } 1,300 \\
\text { cycles }\end{array}$ & & $38.1 \mathrm{~mW} \mathrm{~h} \mathrm{~cm}^{-3}$ & $\begin{array}{l}\text { Wang et al. } \\
\text { (2018b) }\end{array}$ \\
\hline $\mathrm{PANI} / \mathrm{mCC}$ & $\mathrm{PVA}+\mathrm{Zn}\left(\mathrm{CF}_{3} \mathrm{SO}_{3}\right)_{2}$ & $156.4 \mathrm{mAh} \mathrm{g}^{-1}$ & $\begin{array}{l}80 \% \text { after } 1,000 \\
\text { cycles }\end{array}$ & $9742 \mathrm{~W} \mathrm{~kg}^{-1}$ & 185.7 Wh kg ${ }^{-1}$ & $\begin{array}{l}\text { Guo et al. } \\
(2021)\end{array}$ \\
\hline $\mathrm{CNT} / \mathrm{MnO}_{2}-\mathrm{PPy}$ & $\mathrm{ZnSO}_{4}+\mathrm{MnSO}_{4}$ & $222.7 \mathrm{mAh} / \mathrm{g}$ at $0.3 \mathrm{~A} / \mathrm{g}$ & $\begin{array}{l}87.4 \% \text { after } \\
1,000 \text { times }\end{array}$ & & $341.6 \mathrm{Wh} \mathrm{kg}^{-1}$ & Yin et al. (2021) \\
\hline $\mathrm{V}_{2} \mathrm{O}_{5}-\mathrm{Ti}$ & $\mathrm{Zn}\left(\mathrm{CF}_{3} \mathrm{SO}_{3}\right)_{2}+\mathrm{PVA}$ & $377.5 \mathrm{mAh} \mathrm{g}^{-1}$ at $4 \mathrm{~A} \mathrm{~g}^{-1}$ & $\begin{array}{l}68.21 \% \text { after } 500 \\
\text { cycles }\end{array}$ & $6.4 \mathrm{~kW} \mathrm{~kg}^{-1}$ & $622 \mathrm{Wh} \mathrm{kg}^{-1}$ & $\begin{array}{l}\text { Song et al. } \\
(2016)\end{array}$ \\
\hline $\begin{array}{l}\text { binder-free } \mathrm{V}_{2} \mathrm{O}_{5} \\
\text { nanorods }\end{array}$ & $\mathrm{PAM}+\mathrm{ZnSO}_{4}$ & $362.01 \mathrm{mAh} \mathrm{g}^{-1}$ at $0.13 \mathrm{~A} \mathrm{~g}^{-1}$ & $\begin{array}{c}81.9 \% \text { after } 600 \\
\text { cycles }\end{array}$ & $\begin{array}{c}33.4 \mathrm{~mW} \mathrm{~cm} \\
-3\end{array}$ & $10.5 \mathrm{mWh}-\mathrm{cm}^{-3}$ & Lin et al. (2020) \\
\hline
\end{tabular}

extract, under the participation of $\mathrm{Mn}^{2+}$, BZSP, $\mathrm{Zn}_{2} \mathrm{Mn}_{3} \mathrm{O}_{8}$ and $\mathrm{ZnMn}_{2} \mathrm{O}_{4}$ reciprocal transformation (Figure 2B).

On the other hand, the slow kinetics and rapid capacity decay caused by the strong electrostatic repulsion between the divalent zinc ions and the manganese based host crystal structure is one of the important challenges for the practical application of zinc ion batteries. Li's team proposed in-situ growth of manganese dioxide nanorods arrays on three-dimensional porous surface nitrogendoped carbon cloth (N-CC) (Figure 2C). It is not only better than the other nanostructures has higher specific surface area, more active site and better permeability, and can maintain the stability of the structure and electrochemical significantly improve the conductivity at the same time. In addition, it allows a strong covalent coupling based on the nanoscale active material and $\mathrm{N}-\mathrm{CC}$, leading to a fast electron transfer from the active material to the collector. Thus, Under the current density of $0.5 \mathrm{~g} / \mathrm{A}$, flexible-CC@ $\mathrm{MnO}_{2} / \mathrm{N}-\mathrm{CC} @ \mathrm{Zn}$ battery can produce a high capacity of $353 \mathrm{mAh} / \mathrm{g}$ (Figures 2D,E). In addition, the $\mathrm{CV}$ curve of our assembled state $\mathrm{N}$-CC@ $\mathrm{MnO}_{2} / / \mathrm{N}-\mathrm{CC} @ \mathrm{Zn}$ battery hardly changes after 1,000 cycles, which also proves that the cell has good cycle stability. Further, the prepared devices can be bent and twisted in different states without affecting their electrochemical performance (Figures 2F,G). (Qiu et al., 2017)

In addition, many researchers believe that the oxygen vacancy generation and ion intercalation are another effective method to improve the electrochemical performance of $\mathrm{Zn} / \mathrm{MnO}_{2}$ battery. There are two main reasons: On the one hand, as shallow bodies, oxygen vacancies can fundamentally improve the electrical conductivity of manganese-based materials, influence the embedding and de-embedding of metal ions in material layers, reduce the stress and electrostatic repulsion between adjacent layers, directly overcome migration and diffusion barriers, and promote the diffusion and charge transfer of ions during the embedding of metal ions; on the other hand, the electrode material with oxygen vacancy can also generate more electrochemically active sites, increase the surface energy of the system, promote the electrochemical phase transition, and thus possess better charge storage capacity. (Zu et al., 2019; Zhang et al., 2020b).

Zhang's team reported a simple phosphorylation process that introduces oxygen vacancies into phosphate ion intercalated manganese dioxide/vertical multilayer graphene (VMG) arrays to form complete $\mathrm{P}-\mathrm{MnO}_{2-\mathrm{x}} @ \mathrm{VMG}$ cathodes (Figure 2H). By 

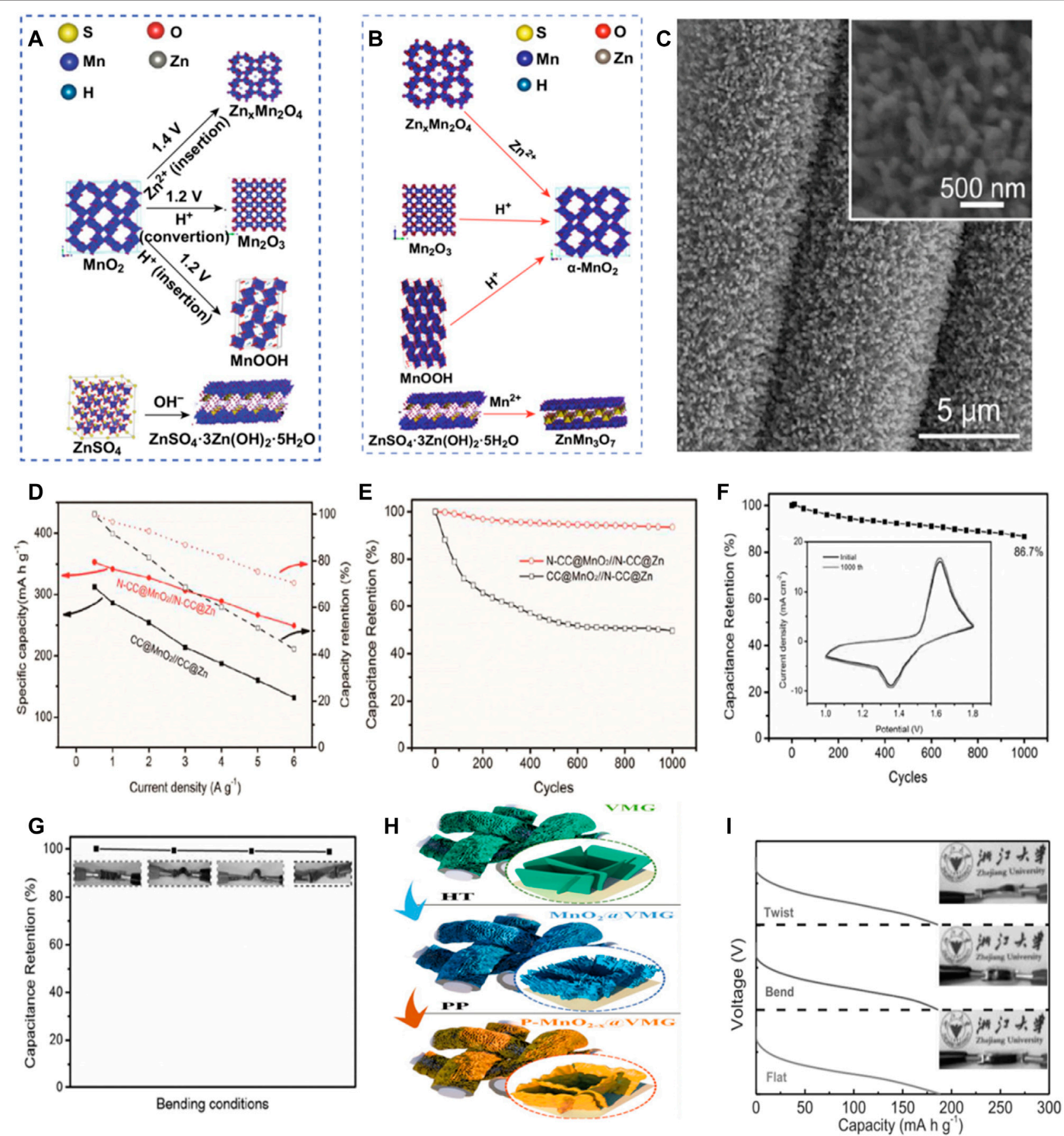

FIGURE 2 | Phase evolution of cathode during the first discharge process (A) and charge process (B). Copyright 2019 Springer. (C)SEM images of the N-CC@ $\mathrm{MnO}_{2}$; inset is the corresponding magnifed SEM image. (D) N-CC@MnO$/ / \mathrm{N}-\mathrm{CC} @ Z n$ and CC@MnO $/ / \mathrm{N}-\mathrm{CC} @ Z n$ the specific capacity and capacity retention rate of the battery as a function of current density (E) Cycling performance of the $\mathrm{N}-\mathrm{CC} @ \mathrm{MnO}_{2} / \mathrm{N}-\mathrm{CC} @ \mathrm{Zn}$ and $\mathrm{CC} @ \mathrm{MnO}_{2} / \mathrm{N}-\mathrm{CC} @ \mathrm{Zn}$ batteries collected at $1 \mathrm{~A} / \mathrm{g}$ for 1,000 cycles. (F) Capacity retention rate of the battery after 1,000 cycles at the current density of $1 \mathrm{~A} / \mathrm{g} \mathrm{N}-\mathrm{CC} @ \mathrm{MnO}_{2} / / \mathrm{N}-\mathrm{CC} @ \mathrm{Zn}$. The CV curves of the first and $1000^{\text {th }}$ cycles are illustrated. (G) At different bending conditions $\mathrm{N}-\mathrm{CC} @ \mathrm{MnO}_{2} / \mathrm{N}-\mathrm{CC} @ Z n$ battery capacity retention rate.Copyright 2017 Journal of Materials Chemistry A. (H) For the synthesis of $\mathrm{MnO}_{2-x} @ \mathrm{VMG}$ shell/core array. (HT, hydrothermal method; PP, phosphorization process). (I) Discharge curves of the device under flat, bending and twisting conditions at $3 \mathrm{~A} / \mathrm{g}$ current density. Copyright 2020 WILEY-VCH Verlag GmbH \& Co. KGaA, Weinheim.

phosphorylation, the oxygen vacancy and phosphorus ion intercalation are realized simultaneously, which improves the electrical conductivity of $\mathrm{MnO}_{2}$ and expands its layer spacing to accelerate ion transfer. In addition, the flexible VMG conductive network provides good peripheral charge transfer and imparts good mechanical strength to the cathode. Thanks to these 
advantages, at the current density of $0.5 \mathrm{~A} / \mathrm{g}, \mathrm{P}-\mathrm{MnO}_{2-\mathrm{x}} @ \mathrm{VMG}$ cathodes shows a high capacity of $302.8 \mathrm{~mA} \mathrm{~h} / \mathrm{g}$ in aqueous electrolytes, and the capacity retention rate is more than $90 \%$ after 1,000 cycles at the current density of $2 \mathrm{~A} / \mathrm{g}$, which proves its long-term cycling stability. In addition, by comparing the $3 \mathrm{~A} / \mathrm{g}$ discharge curves of the battery under flat, bent and twisted conditions, it can be seen that the difference between the three curves is negligible, which proves that the battery has great potential in flexible wearable electronic devices. (Figure 2I). (Zhang et al., 2020c) Mai et al. reported the generation of oxygen vacancies in tunnel $a-\mathrm{MnO}_{2}$ via surface gradient $\mathrm{Ti}$ doping using defect engineering for long-life $\mathrm{Zn}-\mathrm{MnO}_{2}$ batteries. (Lian et al., 2019). Interestingly, the introduction of surface gradient $\mathrm{Ti}$ doping leads to the contraction of the interlayer, but at the same time, the reduction of $\mathrm{Mn}$ valence state leads to the formation of oxygen vacancies compensated by electrons. In addition, Ti substitution and the resulting oxygen vacancy open the $\left[\mathrm{MnO}_{6}\right]$ octahedral wall, resulting in an unbalanced charge distribution and local electric fields in the crystal structure, accelerating ion/electron migration rates. Therefore, the diffusion coefficients of $\mathrm{Zn}^{2+}$ and $\mathrm{H}^{+}$in Ti- $\mathrm{MnO}_{2}$ nanowires are improved. Therefore, $\mathrm{Ti}-\mathrm{MnO}_{2}$ nanowires show improved $\mathrm{H}^{+}$ and $\mathrm{Zn}^{2+}$ storage capacities in $\mathrm{Zn} / \mathrm{MnO}_{2}$ batteries, and achieve excellent high rate capacity and ultra-long cycle stability.

Also, in $\mathrm{ZnSO}_{4}$ electrolytes widely studied, $\mathrm{MnO}_{2}$ usually suffers volume loss due to $\mathrm{Mn}^{3+}$ disambiguation dissolving $\mathrm{Mn}^{2+}{ }^{39} \cdot \mathrm{Mn}^{2+}$ is added to the electrolyte to inhibit the disproportionation of $\mathrm{Mn}^{3+}$, which can effectively inhibit the dissolution of manganese base materials and improve the stability of cathode materials (Pan et al., 2016; Chamoun et al., 2018), but the mechanism is still unclear. For example, in a $\mathrm{Zn}-\mathrm{MnO}_{2}$ cell, dissolution of $\alpha-\mathrm{MnO}_{2}$ is alleviated when $\mathrm{MnSO}_{4}$ is added to a $\mathrm{ZnSO}_{4}$ electrolyte because it can alter the dissolution balance of $\mathrm{Mn}^{2+}$ from the $\alpha-\mathrm{MnO}_{2}$ electrode. (Lian et al., 2019). Zhang and his colleagues reported $\mathrm{MnO}_{2}$ based anode and cathode, zinc added $\mathrm{Mn}\left(\mathrm{CF}_{3} \mathrm{SO}_{3}\right)_{2}$ additives of $\mathrm{Zn}\left(\mathrm{CF}_{3} \mathrm{SO}_{3}\right)_{2}$ electrolytic $\mathrm{Zn}$ $\mathrm{MnO}_{2}$ water of high performance rechargeable batteries. It is found that $\mathrm{Mn}\left(\mathrm{CF}_{3} \mathrm{SO}_{3}\right)_{2}$ can inhibit the dissolution of $\mathrm{Mn}^{2+}$ and form uniform porous $\mathrm{MnO}_{\mathrm{x}}$ nanosheets on the cathode surface, which helps to maintain the integrity of the electrode. It is important to note that beta $\mathrm{MnO}_{2}$ has the high irreversible capacity, stable high rate capability and cycle performance. (Zhang et al., 2017). In addition, coating can also be used to alleviate the dissolution of mangan-based materials. For example, Yang et al. prepared an independent flexible film (Designated as $\mathrm{CNT} / \mathrm{MnO}_{2}-\mathrm{PPY}$ ) composed of carbon nanotubes and polypyrrole coated manganese dioxide nanowire through insitu reactive self-assembly and vacuum filtration. The Polypyrrole (PPy) coating improves the conductivity of $\mathrm{MnO}_{2}$ NWs, alleviates the dissolution of cathode materials and provides a strong buffer to accommodate large volume changes during repeated cycles. (Zhang et al., 2020d).

\section{Silver-Based Materials}

Zinc-silver batteries have the following advantages: high specific energy (theoretical specific capacity: $432 \mathrm{mAh} / \mathrm{g}$ ), high discharge efficiency, moderate charging efficiency, smooth discharge voltage, small self-discharge rate, long dry storage life and good mechanical properties. (Kumar et al., 2019; Tan et al., 2018). At the same time, zinc-silver batteries also have obvious shortcomings, which are as follows: very high cost, short life, poor low-temperature performance and not resistant to overcharging. The silver oxide button battery has widely used in electronic watches, calculators, small instruments and other micro electrical appliances as power supply because of their above-mentioned advantages. In recent years, a lot of research has been done to make these batteries flexible. In addition, Wang's team has developed a printable, polymer-based zinc-silver oxide (AgO$\mathrm{Zn}$ ) battery with flexibility, rechargeability, high area capacity and low impedance. The redox reactiondepends on the zinc ions $\left(\mathrm{Zn}^{2+}\right)$ and silver ions dissolved in alkaline electrolyte $(\mathrm{Ag})$ and the supersaturated induced precipitation. In addition, due to the high oxidation state, make full use of line printing batteries can realize $>54 \mathrm{~mA} \mathrm{~h} / \mathrm{cm}^{2}$ area of high capacity (Figure 3A) while maintaining a low internal resistance (Figure $\mathbf{3 B}$ ). The battery can still charge and discharge normally without multiple deformations affecting its rechargeability (Figures 3C,D). Overall, printed thin film $\mathrm{AgO}-\mathrm{Zn}$ thin film batteries combine superior electrochemical and mechanical properties and prove to be well suited for reliably and sustainably powering a wide variety of wearable and flexible electronic devices. In addition, Meng and his colleagues used polystyrene block polyisoprene block polystyrene (SIS) as a hyperelastic adhesive for printing inks to print a $\mathrm{Zn}-\mathrm{Ag}_{2} \mathrm{O}$ battery with high ductility and a reversible capacity density of $2.5 \mathrm{mAh} / \mathrm{cm}^{2}$ even after repeated $100 \%$ stretching.Two stretchable battery with "NANO" design printed directly on the seal on the spandex thermoplastic polyurethane (PU) the top of the head (Figure 3E). On the "NANO" current collector, electrodes are printed separately to form two "NA" and "NO" batteries designed to be connected in series to power the $3 \mathrm{~V}$ wearable LED (Figure 3F). Regardless of the serious torsional strain (Figure 3G), indentation (Figure 3H), $100 \%$ uniaxial tensile (Figure 3I) and biaxial stretching, stretching "NANO" to the battery can keep constant LED brightness (Figure 3J). The battery energy provided so far reported the highest reversible capacity of the inherent scalability battery size and discharge current density. New stress wear-resisting printing inks for the wide application of flexible paved the way to the further development of the electronic products. The new printed battery based on SIS can withstand severe bending caused by the wearer's movement. (Kumar et al., 2016).

\section{Conductive Polymers}

Compared with metal oxides, conductive polymers exhibit higher conductivity due to their long $\pi$-electron conjugated system (Shi et al., 2018), and also has the advantages of low cost, easy synthesis, and excellent mechanical properties (Cong et al., 2021), are excellent cathode materials for $\mathrm{Zn}$ batteries, and show promising energy storage behavior. Therefore, conductive polymers have attracted wide attention in the field of electric energy storage, especially in wearable electronic devices. Polyaniline (PANI) is one of the most common type of conductive polymers. Polyaniline is easy 

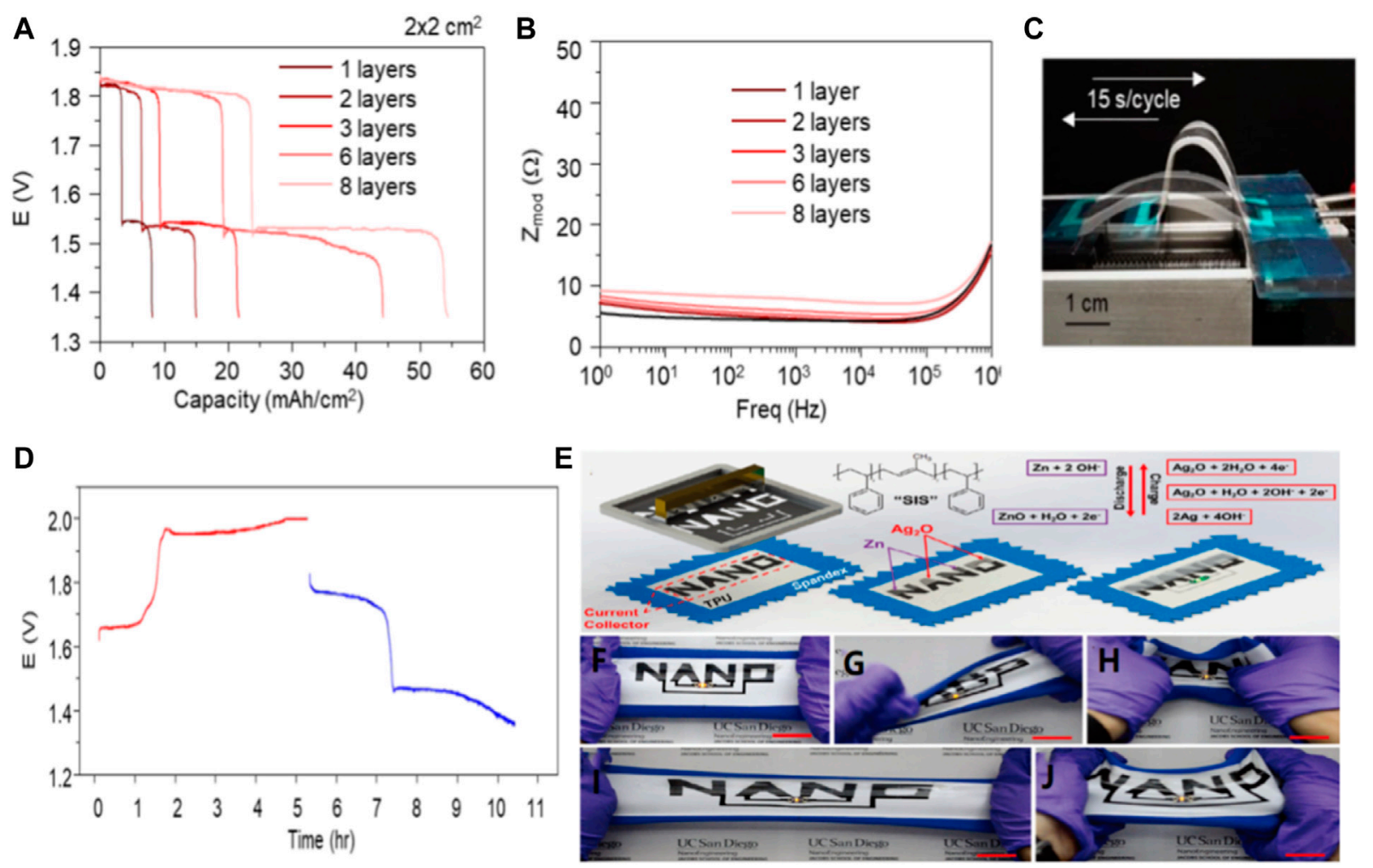

FIGURE 3 | (A) Electrochemical performance of AgO-Zn batteries as galvanic cells. The active material load is the capacity of the $2 \times 2 \mathrm{~cm}{ }^{2}$ battery with $1-8$ layers. (B) Bode plot reflecting the corresponding impedance of the $2 \times 2 \mathrm{~cm}^{2}$ cells with different areal loading. (C) Diagram of a cell controlled by a linear stage at a speed of 15 s/cycle under repeated $180^{\circ}$ bending cycles, and (D) corresponding volt-time curves for charging (red) and discharging (blue) of the cell during approximately $\sim 2,500$ repeated bending cycles. Copyright 2020 Research Gate. (E) Screen printing steps for $\mathrm{Zn}-\mathrm{Ag}_{2} \mathrm{O}$ cells on stretchable fabric using SIS adhesive. Illustration: REDOX charging-discharging reaction. Photographs of the sealed cell during (F) horizontal stretching, (G) distortion, (H) indentation strain, (I) $100 \%$ stretching and (J) biaxial stretching. Copyright 2016 Advanced Energy Materials.

to synthesize and has high electrical conductivity and electrochemical activity. (Eftekhari et al., 2017). It as a stream of zinc ion battery cathode material has been widely studied. However, it suffers from rapid deactivation and consequent performance deterioration due to spontaneous deprotonation during charging/discharging, and has the disadvantage of poor cycling stability in high $\mathrm{pH}$ solutions, which limits its further application in polyaniline zinc batteries. Therefore, Yang's group reported a strategy to introduce $\left[\mathrm{Fe}(\mathrm{CN})_{6}\right]^{4-}$, in which the nitrogen atoms on the polyaniline chain may also interact with $\left[\mathrm{Fe}(\mathrm{CN})_{6}\right]^{3-}$ / $\left[\mathrm{Fe}(\mathrm{CN})_{6}\right]^{4-}$ to affect the electrochemical stability of polyaniline. Considering these factors, $\left[\mathrm{Fe}(\mathrm{CN})_{6}\right]^{3-} /$ $\left[\mathrm{Fe}(\mathrm{CN})_{6}\right]^{4-}$ and polyaniline chain between the REDOX reaction and hydrogen bonding may be beneficial to the electrochemical properties of polyaniline, which can greatly improve the cycle stability of the polyaniline electrode, at the same time maintain its initial high specific capacity (Figure 4A). After 1,000 times charging and discharging cycle, CC-PANI-FeCN capacity retention rate of about $71 \%$, and the capacity of the CC-PANI retention rate is only $17 \%$ (Figures $4 \mathbf{B}, \mathbf{C}$ ). Assembly of quasi solid flexible zinc ion battery under the condition of different bending the specific capacity and coulomb efficiency is close to $100 \%$, suggest that the potential of as flexible energy storage device (Figure 4D). (Yao et al., 2020)

In addition, Huang's team reported a method to improve the electrochemical reactivity and stability of the polyaniline cathode by constructing a pile-electron conjugate system between PEDOT: PSS on polyaniline and carbon nanotubes. The cathode can provide a high capacity of $238 \mathrm{mAh} / \mathrm{g}$ at a current density of $0.2 \mathrm{~A} / \mathrm{g}$, with good rate performance and good cycle stability (Figure 4E). Zinc ion batteries based on post-treated CNT PANI PEDOT: PSS ( $\mathrm{t}$-CNTs-PA-PE)showed good cycle stability and almost $100 \%$ cycle efficiency in 1,500 cycles. Moreover, Solid ZIBs in the bending and hammering process, the capacity loss is not obvious, keep in more than $90 \%$ of the original capacity (Figures $\mathbf{4 F}, \mathbf{G}$ ). This work demonstrates that conductive polymer cathodes can be used in high-performance ZIBs to meet the needs of flexible electronics. (Liu et al., 2019a).

\section{Prussian Blue Materials}

PBA with the formula of $\mathrm{A}_{\mathrm{x}} \mathrm{M}_{\mathrm{y}}\left[\mathrm{B}(\mathrm{CN})_{6}\right]_{\mathrm{z}} \mathrm{mH}_{2} \mathrm{O}(\mathrm{x}, \mathrm{y}, \mathrm{z}, \mathrm{m}=$ stoichiometric numbers; $\mathrm{A}, \mathrm{B}=$ alkaline metal; $\mathrm{M}=\mathrm{Zn}^{2+}, \mathrm{Ni}^{2+}, \mathrm{Cu}^{2+}$, etc.) is constructed by a $3 \mathrm{D}$ network of zeolitic struc-ture. (Xu et al., 2017). It has open skeleton structure, sufficient REDOX 

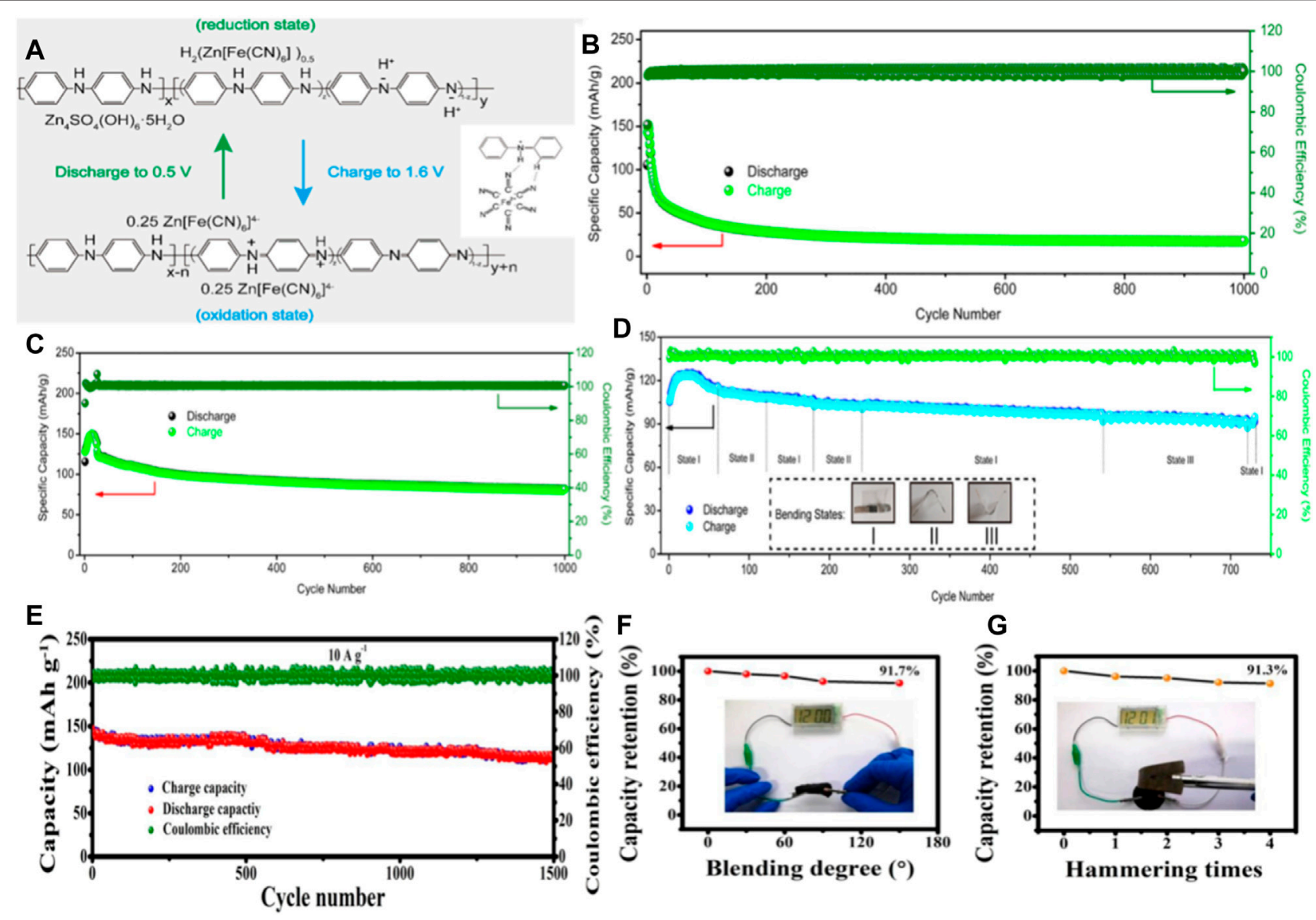

FIGURE 4 | (A) REDOX mechanism of CC-PANI-FeCN. Illustration[Fe(CN)6 $]^{4-}$ Schematic diagram of interaction with PANI. Cyclic properties of CC-PANI (B) and CC-PANI-FeCN (C) at current density 5 A g. (D) The optical images ofquasi-solid-stateflexible batteries in different bending states. Copyright 2020 Chemical Engineering Journal. (E) Cycling performance of t-CNT-PA-PE cathode in ZIBs at current density of $10 \mathrm{~A} / \mathrm{g}$. Capacity retention of solid ZIBs under different destructive tests, including (F) bending test and (G) hammer testCopyright 2019 ACS Appl Mater Interfaces.

active center and relatively strong structural stability (Jia et al., 2015; Zhang et al., 2015; Song et al., 2018). The open framework endows PBA to be promising candidate for $\mathrm{Zn}^{2+}$ storage. However, Prussian blue analogues have a low capacity (less than $100 \mathrm{mAh} / \mathrm{g}$ ) because the active sites are underutilized and in most cases are single-atom REDOX (Ma et al., 2019a). It is still challenging to further improve the specific capacity and cycling stability of PBA cathodes.

$\mathrm{Lu}$ and his colleagues prepared manganese oxide coated zinc ferrite $(\mathrm{ZnHCF})$ nanocubes $\left(\mathrm{ZnHCF} @ \mathrm{MnO}_{2}\right)$ by in situ coprecipidation method (Lu et al., 2017). The composite has a unique structure that has a synergistic effect by combining the capacitive and intercalated properties of the two components with the REDOX reaction, thus regulating the storage of $\mathrm{Zn}$ ions. Therefore, $\mathrm{ZnHCF}$ nanocubes encapsulated by $\mathrm{MnO}_{2}$ nanocubes have a high capacity of $\mathrm{Zn}$ ion storage and discharge, and their working voltage can reach $\sim 1.7 \mathrm{~V}$. In order to demonstrate the practical application of zinc ion battery in the field of flexible wearable electronics, a flexible quasi-solid-state battery was prepared by coupling ZnHCF@ $\mathrm{MnO}_{2}$ with $\mathrm{Zn}$ thin foil in $\mathrm{ZnSO}_{4} / \mathrm{PVA}$ gel electrolyte. At different bending angles, the battery's current changes are negligible, showing excellent flexibility (Figure 5A). In addition, the discharge capacities of the flexible device at $100,200,400,500$ and $800 \mathrm{~mA} / \mathrm{g}$ are $89,78,67,58$, and $53 \mathrm{mAh} / \mathrm{g}$, respectively (Figure 5B). In addition to higher discharge capacity, quasi-solid state batteries also have higher rate capacity (Figure 5C). When the current density increases from $100 \mathrm{~mA} / \mathrm{g}$ to $800 \mathrm{~mA} / \mathrm{g}$, the discharge capacity can still exceed $49 \mathrm{~mA} \mathrm{~h} / \mathrm{g}$, and the capacity retention rate is $55 \%$. At the same time, flexible battery can be stable cycle more than 500 times, can maintain about 71 percent of the capacity. Even flexible battery folding can power LED bulbs (drive voltage is $1.8 \mathrm{~V}$ ). (Figure $5 \mathrm{D}$ ).

Zhi and his colleagues incorporated $\mathrm{Co}(\mathrm{II}) / \mathrm{Co}(\mathrm{III})$ and $\mathrm{Fe}(\mathrm{II}) / \mathrm{Fe}$ (III) REDOX reactions into cobalt hexocyanate $\left(\mathrm{CoFe}(\mathrm{CN})_{6}\right)$, which is a breakthrough to realize the combination of high capacity and high voltage waterbearing zinc ion batteries. (Ma et al., 2019a). The Zn/ $\mathrm{CoFe}(\mathrm{CN})_{6}$ battery utilizes two pairs of $\mathrm{Co}(\mathrm{II}) / \mathrm{Co}(\mathrm{III})$ and $\mathrm{Fe}(\mathrm{II}) / \mathrm{Fe}(\mathrm{III}) \mathrm{REDOX}$ reactions to provide a high operating voltage platform of $1.75 \mathrm{~V}$ and a high capacity of $173.4 \mathrm{~mA} \mathrm{~h} / \mathrm{g}$ 
A
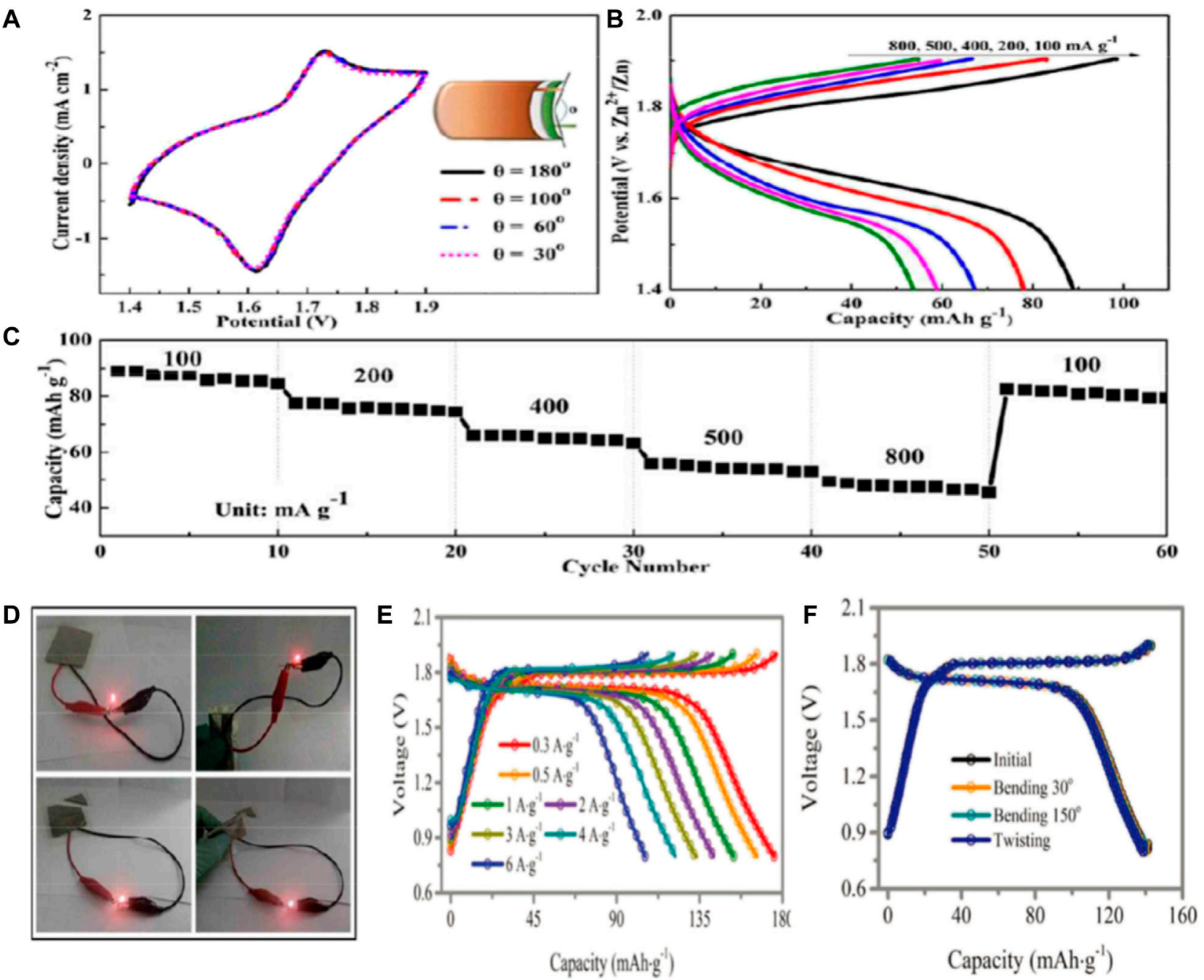

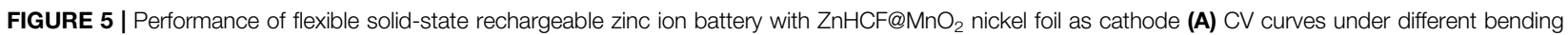
conditions at $1 \mathrm{mV} / \mathrm{s}$; (B) Charge-discharge curves under different current densities; (C) Multiplier performance of flexible cells; (D) Photographs of the flexible zinc batteries powering the LED bulbs in their original and cut state respectively Copyright $2017 \mathrm{~J}$. Mater. Chem. A. Electrochemical performance of Zn/CoFe(CN) 6 cells with $4 \mathrm{~m} \mathrm{Zn(OTf})_{2}$ electrolyte (E) constant current charge-discharge curves under different current densities; (F) Solid-state cable battery: constant current chargedischarge curve and torsional deformation of battery at different bending angles of $60^{\circ}$ and $150^{\circ}$ when the fixed device length is $10 \mathrm{~cm}$ and bending radius is $1 \mathrm{~cm}$.

at $0.3 \mathrm{~A} / \mathrm{g}$. The $3 \mathrm{D}$ open structure of the battery provides $\mathrm{A}$ sufficiently high discharge capacity of $109.5 \mathrm{~mA} \mathrm{~h} / \mathrm{g}$, even at an extremely fast charge/discharge rate of $6 \mathrm{~A} / \mathrm{g}$. (Figure $5 \mathrm{E}$ ). In addition, the $\mathrm{Zn} / \mathrm{CoFe}(\mathrm{CN})_{6}$ battery achieved excellent cycle performance of 2,200 times and coulomb efficiency of nearly $100 \%$. Furthermore, sol-gel of hydrogel electrolyte has been developed to prepare high-performance flexible cable batteries. The battery has excellent electrochemical performance, uniform torsional deformation and excellent mechanical properties at bending degrees of $60^{\circ}$ and $150^{\circ}$. (Figure 5F). This strategy enables the active material to fully contact the electrolyte, thus improving the electrochemical performance (capacity increase of $\approx 18.73 \%$ ) and mechanical stability of the solid-state device.

\section{Vanadium Base Material}

Vanadium cathode because of its excellent REDOX chemistry, can promote the open of insert/take off layer response the main structure and high specific capacity and aroused people's great interest. (Wang et al., 2017; Guo et al., 2018). Among various vanadium based oxides, $\mathrm{V}_{2} \mathrm{O}_{5}$ has good potential as $\mathrm{ZB}$ cathode material due to its high theoretical capacity $(589 \mathrm{~mA} \mathrm{~h} / \mathrm{g})$ based on double electron transfer. The main challenge facing $\mathrm{V}_{2} \mathrm{O}_{5}$ cathode is that the $\mathrm{V}_{2} \mathrm{O}_{5}$ cathode synthesized by traditional methods has insufficient active sites, low conductivity, making its ultra-fast charging performance and high rate performance far below expectations.

Mai and colleagues designed a novel cathode material by growing two-dimensional $\mathrm{V}_{2} \mathrm{O}_{5}$ nanosheets directly on a 

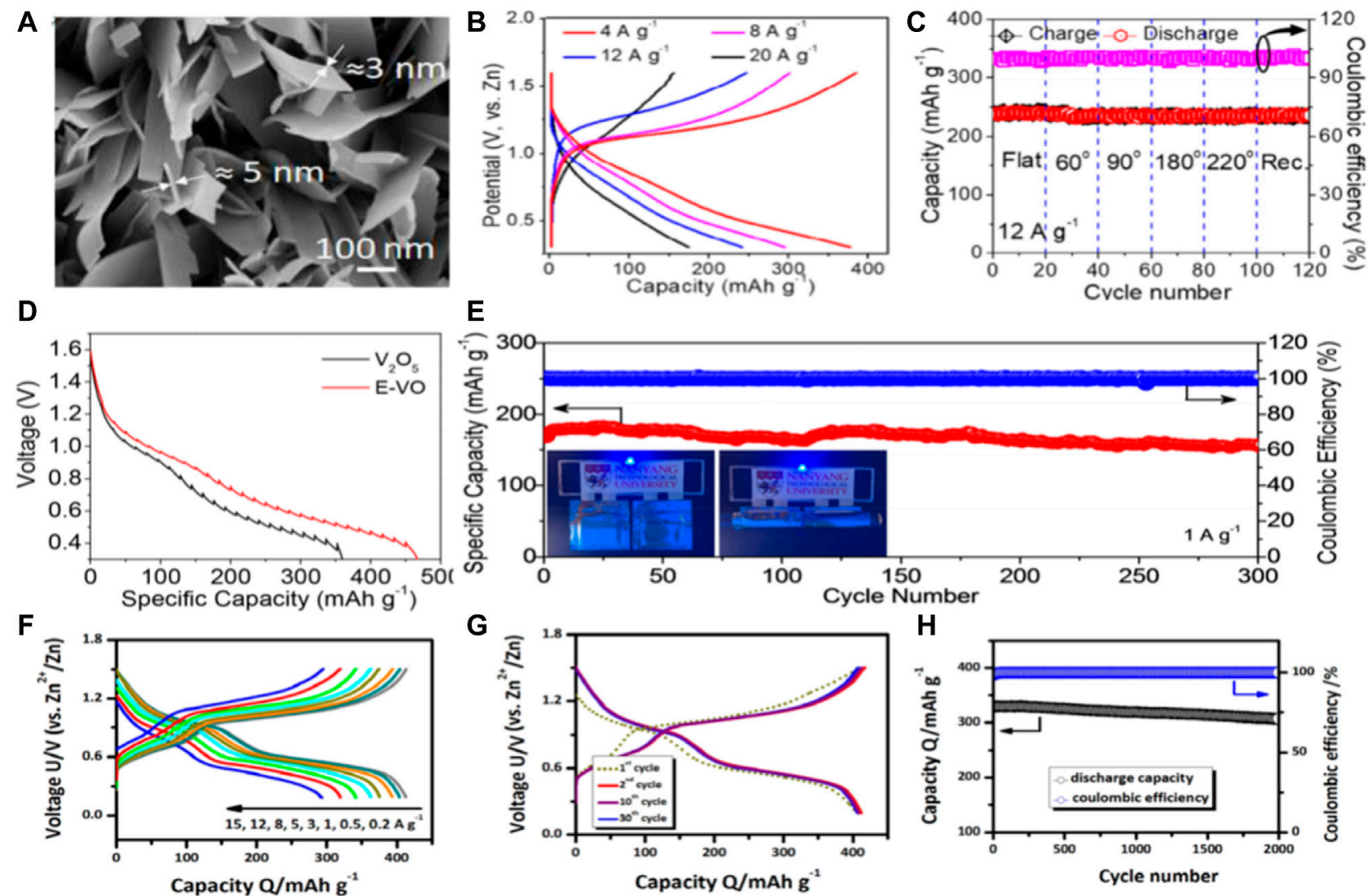

Cvcle number
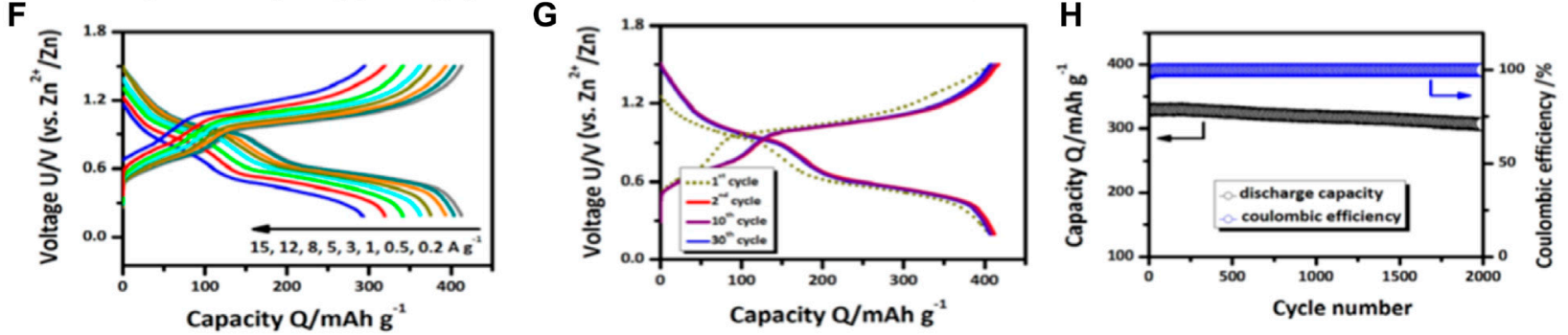

FIGURE 6 | (A) High power FESEM images of $\mathrm{V}_{2} \mathrm{O}_{5}$ nanosheets grown directly on titanium substrates, (B) Charge-discharge curves of at various current densities in potential window of 0.3-1.6 V, (C) Charge-discharge profiles during different bending states at constant current density of $12 \mathrm{~A} / \mathrm{g}$. Copyright 2020 Elsevier Ltd. (D) Discharge GITT curves at a current density of $0.05 \mathrm{~A} / \mathrm{g}$,(E) Cycling stability and Coulombic efficiency at $1 \mathrm{~A} / \mathrm{g}$. Inset in (E) shows the blue LED light up by two flat or bending state flexible quasi-solid-state Zn/E-VO batteries. Copyright 2019 NANOEN 3724. (F) Charge/discharge curves of the DVOC sample at different current densities. (G) Charge/discharge curves of the DVOC sample during the initial thirty cycles. (H) High-rate long-term cycling properties of the DVOC sample at 10 AVg. Copyright 2020 ChemSusChem.

flexible titanium (Ti) substrate. (Javed et al., 2020). The resistance of $2 \mathrm{D} \mathrm{V}_{2} \mathrm{O}_{5}$ nanosheets is greatly reduced and provides more active sites to facilitate electrochemical reactions in zinc ion batteries. Meanwhile, the improvement of the electrochemical performance of $\mathrm{V}_{2} \mathrm{O}_{5}$-Ti cathode is due to the unique structure of vertically arranged ultra-thin nanosheets (Figure 6A) which ensures that $\mathrm{Zn}^{2+}$ has a larger embedding space and a shorter diffusion length, thus improving the electrochemical performance and providing ultra-fast charging performance. An ultra-fast and flexible quasi - solid $\mathrm{F}-\mathrm{V}_{2} \mathrm{O}_{5}-\mathrm{Ti} / / \mathrm{Zn}$ battery was developed. The capacity, power density and energy density parameters are better than those of the previously reported waterbased/flexible zinc ion battery. (Figures 6B,C).

Yan and colleagues propose a simple in situ method that simultaneously introduces polyvalence to increase the interlayer water content and enlarge the interlayer distance of hydrated $\mathrm{V}_{2} \mathrm{O}_{5}$. (Zhao et al., 2019). These structural adjustment makes the layered expansion $\mathrm{V}_{2} \mathrm{O}_{5} 2.2 \mathrm{H}_{2} \mathrm{O}(\mathrm{E}-\mathrm{VO})$ nano piece has faster charge transfer kinetics, $\mathrm{Zn}^{2+}$ storage space and more than precursor $\mathrm{V}_{2} \mathrm{O}_{5}$ higher structural stability. (Figure 6D). As cathode of water-based $\mathrm{ZIB}, \mathrm{E}-\mathrm{VO}$ has the high irreversible capacity $(450 \mathrm{~mA} \mathrm{~h} / \mathrm{g}$ at $0.1 \mathrm{~A} / \mathrm{g})$, good ability of ratio $(222 \mathrm{~mA} \mathrm{~h} / \mathrm{g}$ at $10 \mathrm{~A} / \mathrm{g})$ and long term stability $(72 \%$ of the capacity to keep 3,000 cycle, at $5 \mathrm{~A} / \mathrm{g}$ ). (Figure 6E).

In addition, the structure crushing and chemical dissolution during the charge-discharge cycle are the main reasons for the electrochemical instability of vanadium oxide. (Yu et al., 2015; Song et al., 2016). In order to solve these problems, regulating the $\mathrm{V}^{4+}$ and the ratio of the $\mathrm{V}^{5+}$ to enhance the electrochemical reaction of reversibility, effectively improve the capacity and stability of the vanadium oxide. An oxygen defect modulated unbonded $\mathrm{V}_{2} \mathrm{O}_{5}$ nanorods (PVO@C) for water/quasi-solid zinc ion batteries were constructed. (Liang et al., 2021). The structure of PVO@C electrode is stable due to oxygen deficiency and phosphorus doping, and the diffusion rate and electronic conductivity of $\mathrm{Zn}^{2+}$ ions are improved. Aqueous PVO@C//Zn cells have significantly increased capacity $(362.01 \mathrm{~mA} \mathrm{~h} / \mathrm{g}$ at 0.13 $\mathrm{A} / \mathrm{g} 1)$ and have remarkable long-term durability (86.7\% capacity after 5,000 cycles and nearly $100 \%$ Coulomb efficiency) compared to the original $\mathrm{VO} / / \mathrm{Zn}$ or $\mathrm{PVO} / / \mathrm{Zn}$ cells. In addition, a stable flexible quasi-solid PVO@C//Zn cell (SS ZIB) was proposed based on flexible PVO@C cathode, elastic Zn anode and PAM gel 
electrolyte. This SS ZIB device achieves an impressive energy density of $10.5 \mathrm{mWh} / \mathrm{cm}^{3}$ at a high power density of $33.4 \mathrm{~W} / \mathrm{cm}^{3}$, exceeding most solid-state batteries previously recorded. After 600 cycles, it has a capacity retention capacity of $81.9 \%$.

Vanadate based materials have the advantages of various element valence states, large theoretical capacity, stable structure and abundant resources, so they are the most widely studied. (Li et al., 2020b; Liao et al., 2020). However, due to strong electrostatic interaction with divalent zinc ion the vanadate cathode has slow kinetics and poor cyclic stability. Deng and colleagues (Lin et al., 2020) constructed a novel vanadate oxide structure and successfully designed a defection-rich $\left(\mathrm{V}_{6} \mathrm{O}_{13}-\delta\right) / \mathrm{C}$ nanovortex to prepare a fibrous flexible DVOC/SWNT@CNTF electrode (SWNT: single-walled carbon nanotube; Carbon nanotube fiber CNTF was prepared). Based on SWNT network and substrate are provided based on CNTF bicontinuous electronic path, promoted the fast dynamics and excellence rate capability (Figures 6F-H).

In addition, the pre-insertion strategy is also an effective method to improve the cycling performance of vanadiumbased zinc ion batteries. Linda F. Nazar and colleagues report a vanadium oxide bronze supported by interlaminar $\mathrm{Zn}^{2+}$ ions and water $\left(\mathrm{Zn}_{0.25} \mathrm{~V}_{2} \mathrm{O}_{5} \bullet \mathrm{nH}_{2} \mathrm{O}\right)$ as the positive electrode of a zinc battery. (vKundu et al., 2016). A reversible $\mathrm{Zn}^{2+}$ ion (de) intercalation storage process with high speed and more than one $\mathrm{Zn}^{2+}$ per formula unit (capacity up to $300 \mathrm{mAh} / \mathrm{g}$ ). The zinc battery has an energy density of $450 \mathrm{~W} / \mathrm{L}$ and a capacity retention rate of more than 80 percent in 1,000 cycles. No dendrites form on the zinc electrode. In order to solve the problem, the preintercalated ions can easily lose the combination with the skeleton and deintercalated into the electrolyte, leading to the collapse of the structure again.Xu reported that the cyclic stability of a zinc ion cell can be improved by preintercalation of tetrapalent tin ions into Pyrovanadate $\mathrm{Sn}_{1.5} \mathrm{~V}_{2} \mathrm{O}_{7}(\mathrm{OH})_{2} \bullet 3.3 \mathrm{H}_{2} \mathrm{O}$ (denoted as $\mathrm{SnVO}$ ). (Xu et al., 2021). Compared with Pure vanadium pentoxide, the tetradvalent tin in SnVO can strongly bind to $\mathrm{V}_{2} \mathrm{O}_{7}{ }^{4-}$ layer, supporting high mechanical stability during zinc ion intercalation. In addition, the tin oxide tetrahedron in the $\mathrm{V}_{4} \mathrm{O}_{10}$ layer can further expand the size of the cavity between Pyrovanadate $\mathrm{V}_{2} \mathrm{O}_{7}{ }^{4-}$, promoting the rapid kinetics of zinc ion diffusion, thus improving the rate performance of ZIB.

\section{Electrolytes}

Electrolyte is another important component of flexible zinc ion battery, which is the "blood" of flexible zinc ion battery and plays an important role in determining its performance in terms of discharge operating time, cycling performance and shelf life. There are two types of electrolytes, one is liquid electrolyte (Hilder et al., 2009), which has a certain disadvantage compared with gel electrolyte because of its fluidity and is prone to side leakage when encapsulating flexible batteries. Next is the solid electrolyte, which contains three main types: hydrogel, ionic conductive inorganic solid and organic polymer. Gel polymer electrolyte is a kind of intermediate state between liquid and solid, which is composed of polymer object and liquid electrolyte. Due to its relatively high ionic conductivity, flexibility and good interfacial contact with electrodes, it has been widely used in flexible zinc ion batteries. In general, the performance of gel electrolytes depends largely on the choice of gelatin and the ratio of each element. The gelatins used to build electrolytes are generally polyvinyl alcohol (PVA), polyethylene oxide (PEO), and polyacrylic acid (PAA) ( $\mathrm{Li}$ et al., 2019a). Polyvinyl alcohol (PVA) is a commonly used polymer matrix with good water retention capacity, which has the characteristics of high hydrophilicity and good film forming ability, excellent chemical stability, electrochemical inertness, durability, non-toxicity and ease of manufacture. (Li et al., 2019b; Fan et al., 2019).

As the evaporation of water, the electrolyte becomes more and more concentrated and the performance of battery deteriorates. To reduce water loss of the electrolyte, thereby improving the ionic conductivity of the electrolyte and the cycle life of battery, Zhong's team has proposed a polymer electrolyte for the body that uses tetraethylammonium hydroxide (TEAOH) as an ionic conductor and polyvinyl alcohol (PVA) as a polymer, with good water retention (Figures 7A,B). The prepared polymer electrolyte maintained a high ionic conductivity of $30 \mathrm{mS} / \mathrm{cm}$ after 2 weeks. In addition, with the commonly used KOH-PVA electrolytic liquid ratio, TEAOH - PVA assembly zinc air battery has excellent discharge properties and cycle life, found no significant degradation in 2 weeks. (Li et al., 2019b).

In addition, the internal pores of the gel electrolyte play a key role in the absorption of electrolytes, electrolytes can be retained in the porous gel electrolytes, and polyethylene glycol as a poreforming agent improves the doping ability and obtain high ionic conductivity. The prepared porous photovoltaic nanocomposite GPE has high ionic conductivity of $57.3 \mathrm{mS} / \mathrm{cm}$, excellent water retention performance and good thermal and mechanical properties under environmental conditions, while the assembled flexible ZAB has excellent cycle stability, discharge performance and power density. (Fan et al., 2019).

In addition to the ionic conductivity and mechanical strength of the hydrogel, certain properties of the polymer electrolyte may have a particular impact on the performance of flexible zinc ion batteries. (Li et al., 2018b). For example, Cui's team reported a novel strategy using thermally reversible polymer hydrogels as functional electrolytes, i.e., using poly (ethylene oxide)-poly (propylene oxide)-poly (ethylene oxide) (PEO-PPO-PEO), with significant structural polymorphism in polar solvents, to provide intelligent cooling recovery for flexible zinc ion batteries. When the cell system is exposed to extreme deformation, a simple cooling process can repair the fractured electrode-electrolyte interface, resulting in in-situ recovery of electrochemical performance compared to conventional flexible cells (Figure 7C). This process can be repeated even after multiple strong folding events, and this cooling-recovery strategy requires only external temperature stimulation without any side effects involving phase transitions. (Zhao et al., 2017).

Soorathep Kheawhom's group also reported a transparent alkaline GPE film, which is polymerized by polyacrylic acid, potassium hydroxide and water as a quasi-solid electrolyteused in zinc-manganese dioxide batteries. The GPE film has high ionic 


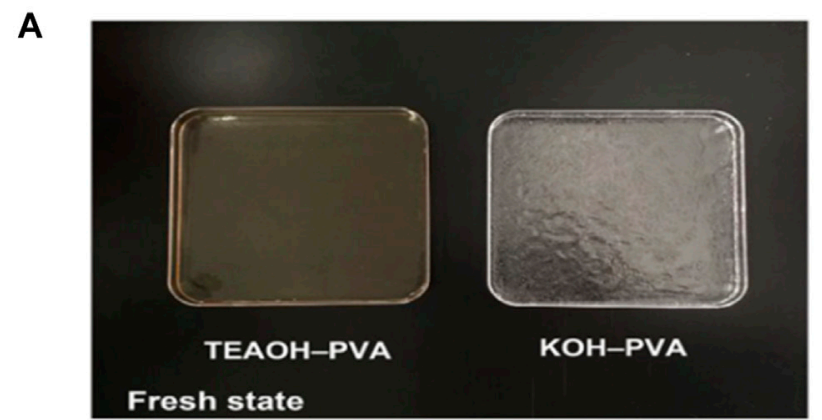

B
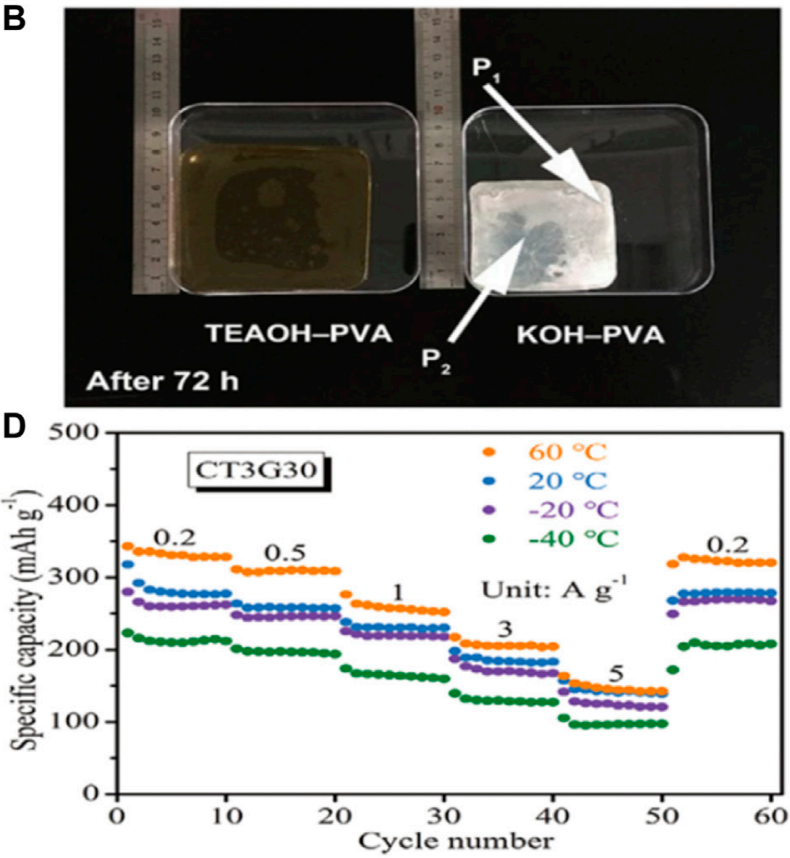
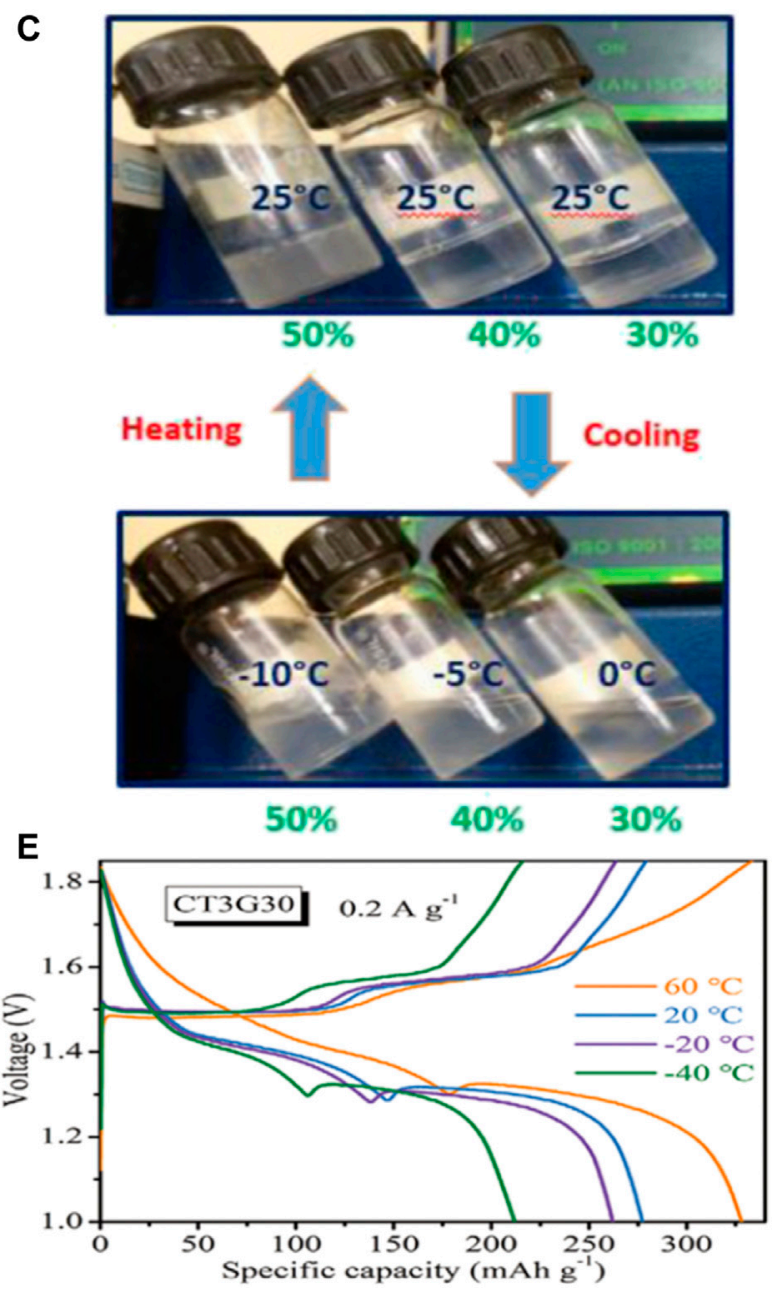

FIGURE 7 | Optical photos of (A) freshly prepared electrolytes and (B) electrolytes stored in the open ambient environment (RH $\left.=30 \%, 20^{\circ} \mathrm{C}\right)$ for $72 \mathrm{~h} . \mathrm{Copyright}$ 2019 Nano Energy. (C) Photographs of PHEs with polymer concentration ranging from 30\% (w/w) to 50\% (w/w) at varied temperatures, showing the thermoreversible gelation behavior. Copyright 2017 Angewandte Chemie International Edition. (D) Rate performance, (E) GCD curves at 0.2 A/g. Copyright 2021 Wiley-VCH GmbH.

conductivity, improveing the cycle life and performance of the battery. (Gaikwad et al., 2011; Lao-atiman et al., 2017).

The application of organic electrolytes in zinc ion batteries is still the least explored field in stable zinc anodes. Due to the higher thermodynamic stability of $\mathrm{Zn}$ to organic solvents, the application of organic solvents may reduce side reactions that may solve the lower Coulombic efficiency (CE) problem by simplifying electrochemistry at the Anode and reducing electrode passivation, thereby reducing dendrite problems.

Wang and colleagues reported that a highly stable and dendrite-free zinc anode was obtained by using triethyl phosphate (TEP) as a cosolvent in aqueous solution. In more than 3,000 h stable galvanized iron/zinc, CE value of $99.68 \%$. The electrolyte and zinc ion battery of zinc anode and six iron acid potassium cyanide copper (KCuHCf) positive electrode showed a good compatibility. The full battery has longer cycle stability and higher rate performance. (Naveed et al., 2019).

However, compared with stream electrolytes, organic electrolytes are less safe, so stream electrolytes are the most widely studied. The flexible zinc ion battery also requires that the electrolyte can withstand the test of bending and folding, and has a certain self-healing ability.

Wong and colleagues developed a simple and economical method to construct a versatile hydrogel electrolyte using cotton as raw material, tetraethyl orthosilicate as crosslinking agent, and glycerin as antifreeze agent (Chen et al., 2021b). The resulting hydrogel electrolyte has high ionic conductivity, excellent mechanical properties (such as high tensile strength and elasticity), ultra-low freezing point, good self-healing ability, high adhesion and good heat resistance. It is worth noting that this water gel electrolyte under $-40^{\circ} \mathrm{C}$ can provide a record of $19.4 \mathrm{mS} / \mathrm{cm}$ high ionic conductivity. Secondly, the hydrogel electrolyte can significantly inhibit zinc dendrite growth and hydrogen evolution side reactions at $-40-60^{\circ} \mathrm{C}$ (Figures 7D,E). Using this hydrogel electrolyte, a flexible quasi-solid $\mathrm{Zn}-\mathrm{MnO}_{2}$ cell was assembled, which showed significant energy density in the $-40-60^{\circ} \mathrm{C}$ range. The battery also shows excellent cycle durability, with high durability in a wide range of harsh 
conditions. In addition, it can be in $>60 \%$ of compression deformation restored to its initial state, shows that it has good elasticity. Zhi's team reported cathodes based on nanofibrillated cellulose (NFC)/polyacrylamide (PAM) hydrogels, electrodeposited Zinc nanoplate anodes, and carbon nanotube (CNT)/a- $\mathrm{MnO}_{2}$ sewable $\mathrm{Zn}-\mathrm{MnO}_{2}$ cells (Wang et al., 2018a). The designed NFC/PAM hydrogel has high mechanical strength and great tensile properties. The prefabricated NFC bone network stabilizes the large pore as a channel for electrolyte diffusion. In addition, the influence of sewing on improving shear resistance of solid battery was analyzed. The sutured $\mathrm{Zn}-\mathrm{MnO}_{2}$ battery retains $88.5 \%$ capacity after 120 stitches and can withstand a large shear force of $43 \mathrm{~N}$.

In order to effectively solve the disadvantage of rapid water loss of hydrogel electrolyte, Liu and colleagues report a solid-state battery based on a self-standing gelatin-based hydrogel electrolyte (GHE) (Han et al., 2018b), whose high ionic conductivity, strong mechanical strength, and tight contact with the electrode enable reversible and stable circulation of $\mathrm{Zn}$ metal anodes and $\mathrm{LiMn}_{2} \mathrm{O}_{4}$ cathodes. Benefiting from superior stability to water, GHE's flexibility and a carefully designed battery structure, the $\mathrm{Zn} /$ $\mathrm{GHE} / \mathrm{LiMn}_{2} \mathrm{O}_{4}$ solid state full battery delivers a high specific capacity of $110.2 \mathrm{~mA} \mathrm{~h} / \mathrm{g}$ and is resistant to cutting, flooding, bending, twisting and crimping. These characteristics of gelatin electrolyte proved beneficial to the battery components and battery performance. When heated, gelatine powder dissolved in AE, which promoted in-situ coating of GHE on the electrode. Using the fast cooling technology after cooling, gelatin solidifies into a solid layer of thin film, to provide mechanical strength to suppress the formation of zinc dendrite.

In a word, the research of flexible zinc ion battery electrolyte mainly focuses on how to alleviate the problem of zinc negative dendrite, hydrogen evolution and solve the problem of hydrogel electrolyte water loss. High performance electrolytes have great influence on the cycle stability, rate performance and energy storage capacity of batteries. (Liu et al., 2019b; Ma et al., 2019b). Therefore, it is of great significance to study electrolytes of flexible Zn-ion batteries.

\section{METHOD OF COMBINING ACTIVE MATERIALS WITH FLEXIBLE SUBSTRATES}

In order to improve the mechanical flexibility of electrodes for wearable electronic devices so that the active material can better adhere to the flexible substrates, flexible electrodes are usually prepared by two ways: one method is to grow the active material directly on the flexible substrate, which is typically carbon cloth, polymer elastomers or textiles. Direct growth of active materials without using any binder, such as catalytic insitu growth, electrodeposition (Liu et al., 2020; Yza et al., 2022), etc. Another method is to load active material with the help of instrument. This includes loading of electrically active material onto flexible substrates by screen printing with the help of adhesives, or loading the active material by inkjet printing, 3D printing, or laser etching with a pre-designed electrode pattern.

\section{In situ Growth Method}

In the preparation of zinc ion batteries, the use of polymer binders and conductive additives results in high contact resistance, which reduces the specific capacity and diversity performance of the battery. An effective strategy to solve this problem is to directly grow the active material in-situ on flexible substrates or collectors as binder-free electrodes. (Wan et al., 2018). This strategy not only ensures fast charge transfer between the active material and the collector, but also enables a uniform distribution of the active material over the collector fluid. Therefore, the prepared flexible electrodes will provide better electrochemical performance, including high capacity, good rate performance and high capacity under deformation conditions.

Yao's team constructed a planar flexible quasi-solid aqueous rechargeable silver-zinc battery using silver nanowires made from a metal-organic framework (MOF) as an unbonded cathode on a carbon cloth. The results show that the ag- $\mathrm{Zn}$ battery has a significant energy density of $1.87 \mathrm{mWh} / \mathrm{cm}^{2}$ due to the abundant reaction sites and short electron and ion diffusion paths provided by the MOF Silver nanowires (Figure 8A). After bending $135^{\circ}$ and cycling 100 times, its capacity remained above $93 \%$ (Figure 8B), which further demonstrates the superb mechanical properties of the prepared devices (Figure 8C). (Li et al., 2018c) In addition, Cai and colleagues prepared threedimensional (3D) integrated binder-free dual-functional oxygen electrodes composed of $\mathrm{NiCo}_{2} \mathrm{O}_{4} @ \mathrm{NiCoFe}$-hydroxide $\left(\mathrm{NiCo}_{2} \mathrm{O}_{4} @ \mathrm{NiCoFe}-\mathrm{OH}\right)$ nanoarrays supported by carbon cloth (Figure 8D). The three-dimensional porous structure and good hydrophilicity of the nitrate-treated carbon cloth substrate facilitated the directional growth of $\mathrm{NiCo}_{2} \mathrm{O}_{4}$ nanocrystals. Therefore, the nickel-iron-hydroxide can randomly anchore and cover on the NiFe surface. Using this controllable and cost-effective in-situ synthesis strategy, the core/ shell structure of $\mathrm{NiCo}_{2} \mathrm{O}_{4} @ \mathrm{NiCoFe}-\mathrm{OH}$ nanoarrays is tightly attached to the $3 \mathrm{D}$ interconnected carbon microfibers. (Figure 8E).The manufactured monolithic binderless oxygen electrode is freestanding and highly flexible/bendable, inheriting a high mechanical strength carbon skeleton. (Li et al., 2020c).

\section{Screen Printing Method}

Many flexible batteries rely on complex, low-production and high-cost manufacturing processes that hinder their transition from the lab to the marketplace, so printed high-performance batteries offer ideas for mass production of flexible batteries. Screen printing is considered to be a cost-effective, easy-tooperate and mass-productable method for the rapid construction of flexible zinc ion cells with precise control performance, flexibility and integration with printed microelectronics. (Guo et al., 2018). Screen printing allows active design control and can potentially combine deterministic and stochastic composites. In order to meet the need for flexibility and scalability while maintaining low cost and using low-cost thick film manufacturing techniques, flexible cell modules can be printed sheet by sheet or roll by roll using traditional and low-maintenance screen printing or scraper casting equipment, thus achieving low-cost mass production of 

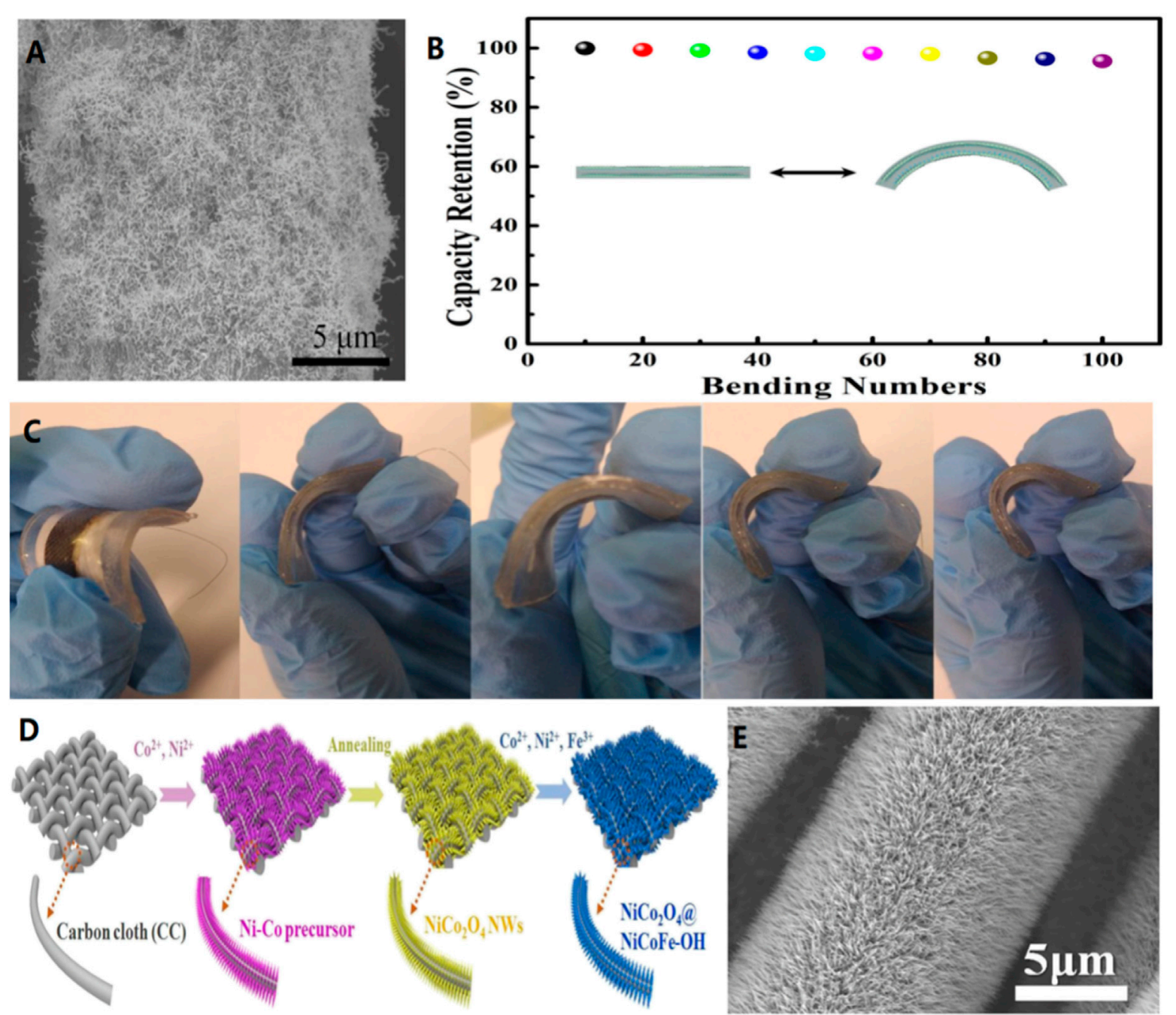

FIGURE 8 | (A) SEM of MOF derived Ag nanowires/CC at Ar/NH 3 . (B) Normalized capacity of the quasi-solid-state Ag-Zn battery bent $135^{\circ}$ for 100 cycles. (C) The photographs of bent quasi-solid-state Ag-Zn battery.Copyright 2018 American Chemical Society. (D) Scheme of the synthetic process of $\mathrm{NiCO}_{2} \mathrm{O}_{4} @ \mathrm{NiCoFe}-\mathrm{OH}$. SEM images of $\mathrm{NiCO}_{2} \mathrm{O}_{4}$ NWs (E) grown on CC. Copyright 2020 Journal of Materials Chemistry A.

flexible batteries (Figures 9A,B). (Kumar et al., 2016; Yin et al., 2021)

Wu's team reports on a cost-effective and industrially applicable screen printing strategy for the rapid and scalable production of rechargeable zinc-manganese dioxide planar batteries with high performance, superior flexibility, scalable applicability and high safety. With zinc ink as anode $(6.4 \mu \mathrm{m}$ thick) and $\mathrm{MnO}_{2}$ ink as cathode ( $9.8 \mu \mathrm{m}$ thick), high-quality graphene ink was used as metal-free collector in neutral electrolyte (2 $\mathrm{M} \mathrm{ZnSO}_{4}$ and $0.5 \mathrm{~m} \mathrm{MnSO}_{4}$ ). Planar unbaffled $\mathrm{Zn} / / \mathrm{MnO}_{2} \mathrm{MBs}$, tested in neutral aqueous solution, has a high capacity of $19.3 \mathrm{~mA} \mathrm{~h} / \mathrm{cm}^{3}$ (corresponding to $393 \mathrm{~mA} \mathrm{~h} / \mathrm{g}$ ) at a current density of $7.5 \mathrm{~mA} / \mathrm{cm}^{3}$, and a significant volume energy density of $17.3 \mathrm{mWh} / \mathrm{cm}^{3}$, superior to lithium film battery $\left(\leq 10 \mathrm{mWh} / \mathrm{cm}^{3}\right)$. In addition, the battery has stable cycling performance, with a capacity retention rate of $83.9 \%$ after 1,300 cycles under $5 \mathrm{C}$, which is better than the previously reported stacked $\mathrm{Zn} / / \mathrm{MnO}_{2}$ battery (Figures 9C,D). (Wang et al., 2020)

Screen printing solves the requirement of high volume production of flexible electrodes at low cost, but faces another difficulty, which is to select or develop the ink formulation and choose the mesh size, as well as the thickness of each layer of ink film forming the anode and cathode, according to the requirements of the amount of active material, electrical properties, electrode stability and electrolyte permeability. (Tehrani et al., 2015). The selection of the mesh is based on the particle size of the mass of active material to be printed. A mesh with too large an aperture loses the significance of screen printing, while a mesh with too small aperture leads to uneven printing of the active material, which in turn affects the electrochemical properties. The right printing template will allow the active substance to be printed more evenly and firmly and to meet the required amount of active substance. 


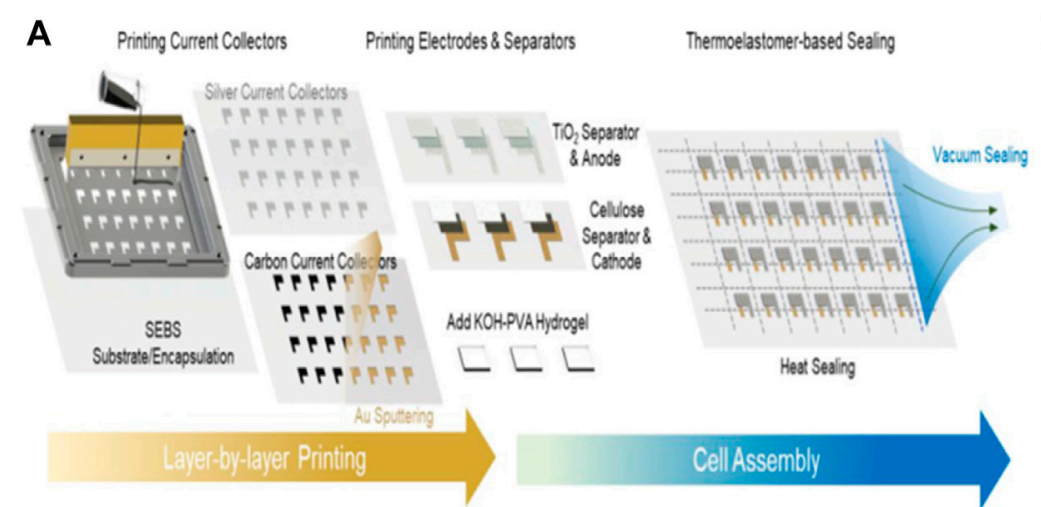

C

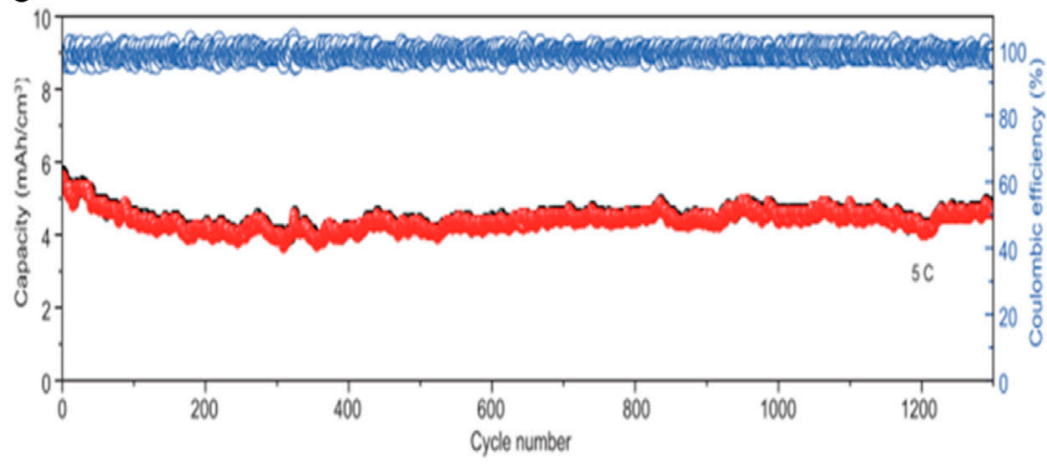

B

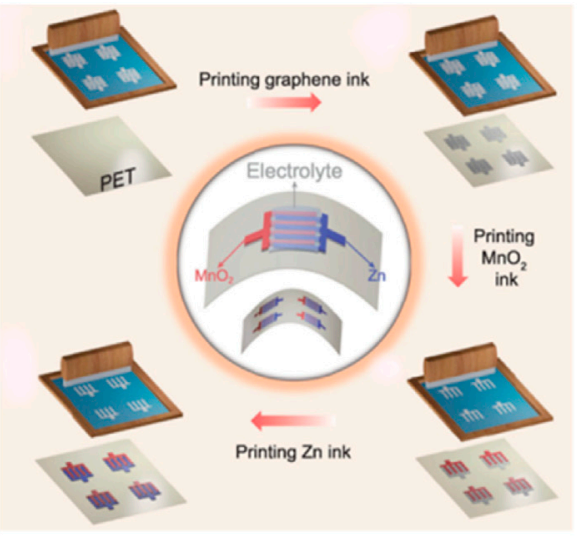

D

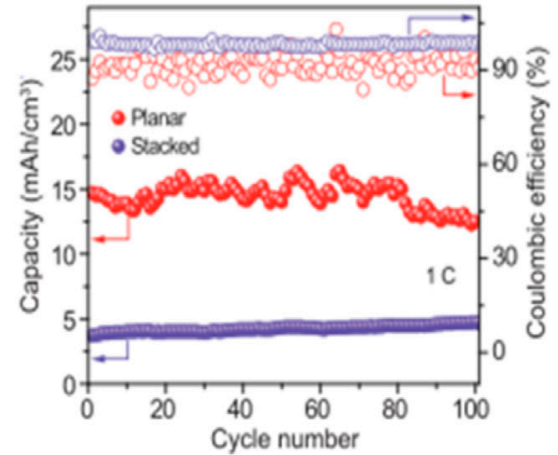

FIGURE 9 | (A) The process of assembling the flexible, rechargeable, and high-capacity AGO-Zn battery is silkscreen printed layer by layer and vacuum sealed. Copyright 2019 ResearchGate. (B) $\mathrm{Zn} / / \mathrm{MnO}_{2}$ planar $\mathrm{MBs}$ was prepared by printing. Schematic diagram of printing zinc//MNO $\mathrm{MB}^{\mathrm{MB}}$ by screen printing method: Blank PETsubstrate, printing graphene collector electrode, printing $\mathrm{MnO}_{2}$ cathode and $\mathrm{Zn}$ anode. Electrochemical performance of printed $\mathrm{Zn} / / \mathrm{MnO} \mathrm{O}_{2}$ planar $\mathrm{MBs}$ (C) cycling stabilities of printed $\mathrm{Zn} / / \mathrm{MnO}_{2} \mathrm{MBs}$ with planar and sandwich-like stacked geometries, measured at a rate of $1 \mathrm{C}$; (D) long-term cycle stability of $\mathrm{Zn} / / \mathrm{MnO} \mathrm{O}_{2}$ planar MBs, with a high rate of 5C over 1,300 cycles. Copyright 2020 Natl Sci Rev.

The rheology of the ink is controlled by a complex formulation of reactive materials, binders and specific solvents. The role of the binder is to bond the ink components and the collector fluid together and to influence whether the active substance will come off. Ink with different ratios of the same active material can also have a great impact on the battery performance. Somenath Mitra's team reported the preparation of printable composite electrodes embedded with multi-walled carbon nanotubes (CNTs) for flexible Ni-Zn batteries. (Wang et al., 2018b). Carbon nanotubes function for electron transport pathways, resulting in better performance than physical mixing of active materials. However, excessive amounts of carbon nanotubes can lead to cracking of the active material. Therefore, it is extremely important to test a suitable ink formulation, which is an inevitable requirement for the preparation of cells with excellent electrochemical properties.

\section{Inkjet Printing Method}

Inkjet printing, as an environmentally friendly and low-cost method for direct deposition of functional nanomaterials, has received widespread attention. Non-contact printing can be achieved on various substrates by programming the print pattern to be printed and then controlling the movement of the print nozzle. The modes of operation for inkjet printing are (i) drop-on-demand (DoD) printing, which delivers droplets caused by thermal bubbles or piezoelectric actuators, and (ii) continuous inkjet (CIJ) printing, which produces a continuous stream of ink through the nozzle by means of an electrostatic field or magnetic field. (Zhang et al., 2020e; Yan et al., 2020).

Ink-jet printing provides the advantage of flexible and wearable electronics manufacturing, such as design of highthroughput, large-scale, good performance, biocompatibility, and on the infinite basal precision deposition. In addition, due to droplet deposition and programmable pattern design, inkjet printing methods greatly reduce the waste of expensive ink materials (Figure 10A).

Chen and his colleagues proposed a heterogeneous metal seedmediated strategy. The basic idea is to print silver nanoparticles on a three-dimensional conductive backbone by inkjet printing and use them as heterogeneous metal seeds to induce uniform nucleation of zinc and avoid dendrite growth during the initial electroplating stage.At the same time, the reaction of $\mathrm{Ag}$ with $\mathrm{Zn}$ produces a zincfriendly $\mathrm{AgZn}_{3}$ alloy as a $\mathrm{Zn}$ resource to compensate for the irreversible loss of active $\mathrm{Zn}$ during the recycling process. In the first 15 cycles, the capacity of the AgNPs@CC/Zn anode cell increased from $182 \mathrm{~mA} / \mathrm{g}$ to $237 \mathrm{~mA} / \mathrm{g}$ and maintained a 

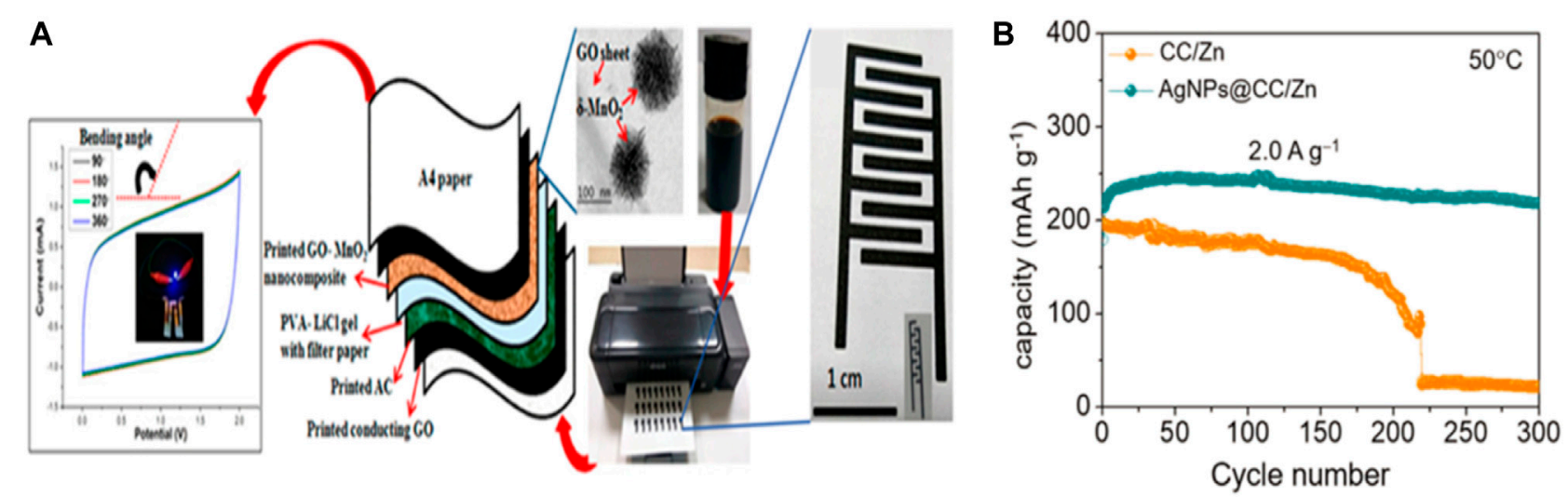

FIGURE 10| (A) Schematic of inkjet-printed $\mathrm{MnO}_{2} / \mathrm{GO}$-based flexible supercapacitors on A4 paper substrates using an EPSON L130 printer. Left: CV curves of the flexible supercapacitors under various bending angles. Reproduced with permission from P. Copyright 2017 American Chemical Society. (B) Use the CC/zinc and AgNPs @ CC/zinc anode NVO lots zinc battery cycle stability under the condition of 50C.Copyright 2021 Advanced Functional Materials.

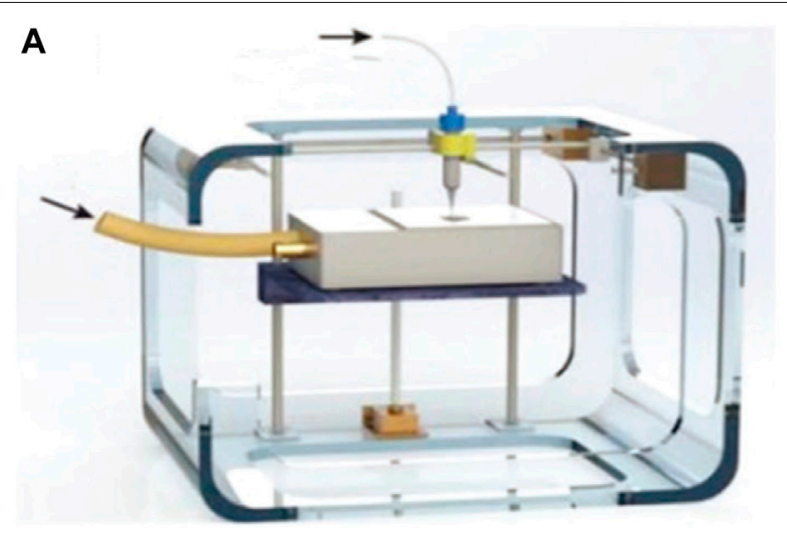

B

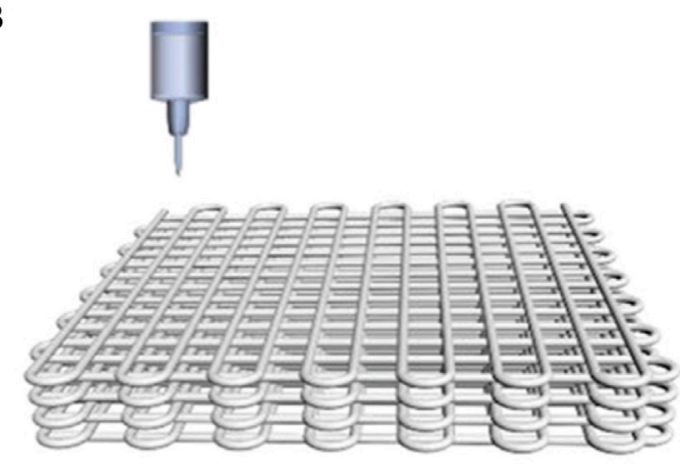

FIGURE 11 | (A) Schematic of the 3D "drop-on-demand" ink jet printer.Copyright 2019, Elsevier. (B) Schematic illustration of 3DP-Zn-E. Copyright 2019, Advanced Functional Materials.

reversible capacity of $218 \mathrm{~mA} / \mathrm{g}$, corresponding to a capacity retention rate of $92 \%$ (Figure 10B). (Chen et al., 2021a)

However, at present, there are still many challenges that the technology is relatively bad. These challenges include preventing nozzle clogging, inhibiting coffee ring effect, and enhancing ink dispersion,etc. (Yan et al., 2020)

\section{Other Methods}

Those climb from claiming 3D printing (3DP) innovation Concerning illustration An revolutionary manufacturing system has created a great attraction for the fabrication of functional electrodes in the field of energy storage and conversion. The printing process usually combines digital programming and manufacturing procedures to rationally design a $3 \mathrm{D}$ functional structural model of the object, followed by the use of special software to obtain sliced layers of the model, which are printed using digital technology material printers, i.e. by adding each twodimensional (2D) layer to the previous one, enabling the construction of a $3 \mathrm{D}$ structure, thus enabling precise control of the spatial geometry and architecture of the device from the macro to the nano scale (Figure 11A). (Pang et al., 2019) Yang's team has demonstrated a $3 \mathrm{D}$ printing system for those development of practical electrodes for zinc-air batteries. The printed anode comprises for large portions minor zinc balls. to enhance the utilization of zinc. The self-supporting air cathode made by $3 \mathrm{D}$ printing has a hierarchical porous structure with high specific surface area, which allows the electrode to have high electrocatalytic activity and fast reaction diffusion channels (Figure 11B). Thanks to these advantages, the assembled zinc-air battery achieves a high releasing capacity of $670 \mathrm{~mA} \mathrm{~h} / \mathrm{g}$ at a current density of $5 \mathrm{~mA} / \mathrm{cm}^{2}$ and a long period cycle stability of at least 350 cycles. (Zhang et al., 2020f).

Laser engraving processing is based on the use of $\mathrm{CNC}$ technology and laser as the processing medium. The physical denaturation of the electrode material by instantaneous melting and vaporization under laser engraving irradiation enables laser engraving to achieve the processing purpose, which in turn completes the preparation of flexible electrodes.Wang's team used a high-precision, simple and low-cost laser engraving technique to 
prepare finger-shaped cathodes and anodes for ZIMB. Suspended finger-like multi-walled carbon nanotube $\mathrm{MnO}_{2}$ (MWCNTs$\mathrm{MnO}_{2}$ ) cathodes were prepared by laser engraving machine (JLK3020) and MWCNTs-Zn anodes based on zinc nanosheets were prepared by laser etching with further acknowledge the full adaptability from claiming ZIMB. The flexible conductive substrate prepared by laser engraving allows ZIMB to exhibit excellent flexibility, resulting in high reliability and stability of ZIMB. The concept proves that the capacity maintenance of ZIMB is up to $96.5 \%$ of the beginning capacity at $120^{\circ}$ bending angle, and even after the 5th self-healing cycle, the capacity retention is still up to $90.2 \%$. This worth of effort gives new plans for outlining another era of high-efficiency, high-reliability and high-stability micro-energy storage devices. (Du et al., 2020).

\section{SUMMARY AND OUTLOOK}

In the era of electronic information technology, electronic devices are developing towards miniaturization and flexibility. Those evergrowing enthusiasm from both academic Group What's more shopper showcase will be activating those fast advancement of new helter skelter execution adaptable vitality stockpiling gadgets. In the research of flexible power supply, flexible zinc ion batteries have been noticed by researchers and have achieved some promising results. In this paper, the research progress of flexible zinc batteries in recent years is reviewed from the following aspects: the differences between different anode, cathode materials and electrolytes in flexible zinc batteries; the method of loading active materials on flexible electrodes are discussed and compared. Although many progresses have been made in this area, it is still highly desirable to solve the following challenges and problems in time to promote the application of flexible zinc batteries.

First of all, the performance of the active materials has a critical impact on the cycling performance and flexibility of the battery. The research of zinc anodes mainly focuses on the material of metal zinc anodes. The primary goal is to reduce the generation of zinc dendrites during long-term cycling, so as to improve the lifetime and electrochemical performance of the battery. Most studies have used zinc foil directly, and some studies have cast zinc and zinc oxide particles on flexible substrates or grow zinc in situ instead of zinc foil in order to obtain better mechanical properties and stability. The research of cathodes is mainly to try to obtain materials with high capacity, high cycling performance, low cost and good mechanical properties, including ion embedding and oxygen vacancy generation for some cathode materials to improve the battery performance. Moreover, the research on the electrolyte of flexible zinc ion battery mainly focuses on the gel electrolyte. It consists of polymer body and liquid electrolyte, which has relatively excellent flexibility performance and can basically meet the needs of flexible zinc ion battery, and also has relatively good ionic conductivity to improve the multiplication performance of flexible zinc ion battery, as well as can make good interfacial contact with electrode.

Secondly, the main technologies for loading active materials onto flexible electrodes include in-situ growth method, screen printing, and inkjet printing and so on. Among them, the in-situ growth of active materials does not require binder, which ensures rapid charge transfer between active materials and collectors, makes the active material evenly distributed on the collector, so that the prepared flexible electrodes have better electrochemical performance. Screen printing is a sheet-by-sheet or roll-by-roll printing method for flexible cell, which is considered to be a costeffective, easy-to-handle and mass-producible process. Inkjet printing can programmed according to the pattern to be printed, enabling non-contact printing on a variety of substrates, resulting in low-cost, high-precision, high-efficiency electrode printing, which can be used for artificial intelligence equipment, special-shaped battery and private customization.

With the innovation of technology, flexible zinc ion battery has a wide application prospect in flexible electronic devices due to its excellent performance. The development of wearable/ implantable electronic devices such as flexible display devices, health monitors and electronic sensors has attracted more and more attention from academia and industry. One of the biggest challenges in the development of flexible electronic devices is to develop flexible, light, thin and safe portable energy storage devices. Flexible water zinc ion batteries are safe, can meet safety performance, and can be designed to fit into clothing and other wearable devices. The batteries must better fit the shape of wearable devices to avoid being bulky. Therefore, the development prospect of flexible zinc ion battery is broad.

Despite the advantages of flexible zinc batteries, there are still many problems for researchers to continue to study: (1) compared with the high theoretical capacity of the zinc metal anode, the cathode active material with higher capacity need to be explored; (2) the stability of the zinc negative electrode at high current and high capacity needs to improved; (3) in flexible batteries, with movements such as bending, the loaded active material usually cracks or flakes off, leading to a rapid decline in electrochemical performance. Therefore, it is necessary to design the ideal electrode material structure or improve the process method of loaded active material, and then further improve the mechanical properties of the electrode; (4) to further increase the actual capacity of flexible zinc batteries while improving the mechanical properties of electrodes. How to encourage the capacity of zinc ion batteries by increasing the amount of loaded active substance, which in turn has wider practicality.

\section{AUTHOR CONTRIBUTIONS}

All authors listed have made a substantial, direct, and intellectual contribution to the work and approved it for publication.

\section{FUNDING}

This work was financially supported by the National Natural Science Foundation of China (61904097), the Shandong Scientific Research Awards Foundation for Outstanding Young Scientists (No. ZR2018BEM030), Scientific Research Foundation of Shandong University of Science and Technology for Recruited Talents (No. 2017RCJJ058) and the Program for Tsingtao Al-ion Power and Energy-storage Battery Research Team in the University. 


\section{REFERENCES}

Alfaruqi, M. H., Islam, S., Putro, D. Y., Mathew, V., Kim, S., Jo, J., et al. (2018). Structural Transformation and Electrochemical Study of Layered MnO2 in Rechargeable Aqueous Zinc-Ion Battery. Electrochimica Acta 276, 1-11. doi:10. 1016/j.electacta.2018.04.139

Chamoun, M., Brant, W. R., Tai, C.-W., Karlsson, G., and Noréus, D. (2018). Rechargeability of Aqueous Sulfate $\mathrm{Zn} / \mathrm{MnO} 2$ Batteries Enhanced by Accessible Mn2+ Ions. Energ. Storage Mater. 15, 351-360. doi:10.1016/j.ensm.2018.06.019

Chen, M., Chen, J., Zhou, W., Han, X., Yao, Y., and Wong, C. P. (2021). Realizing an All-Round Hydrogel Electrolyte toward Environmentally Adaptive Dendrite-free Aqueous $\mathrm{Zn}-\mathrm{MnO}_{2}$ Batteries. Adv. Mater. 33 (9), e2007559. doi:10.1002/adma.202007559

Chen, T., Wang, Y., Yang, Y., Huang, F., Zhu, M., Wei Ang, B. T., et al. (2021). Heterometallic Seed-Mediated Zinc Deposition on Inkjet Printed Silver Nanoparticles toward Foldable and Heat-Resistant Zinc Batteries. Adv. Funct. Mater. 31 (24). doi:10.1002/adfm.202101607

Cong, Z., Guo, W., Zhang, P., Sha, W., Guo, Z., Chang, C., et al. (2021). Wearable Antifreezing Fiber-Shaped Zn/PANI Batteries with Suppressed Zn Dendrites and Operation in Sweat Electrolytes. ACS Appl. Mater. Inter. 13 (15), 17608-17617. doi:10.1021/acsami.1c02065

Dong, H., Li, J., Guo, J., Lai, F., Zhao, F., Jiao, Y., et al. (2021). Insights on Flexible Zinc-Ion Batteries from Lab Research to Commercialization. Adv. Mater. 33 (20), e2007548. doi:10.1002/adma.202170158

Du, X., Shi, J., Chen, Z., Ni, T., Li, J., Ruan, L., et al. (2020). A Laser Etched Zinc Ion Microbattery with Excellent Flexibility and Self-Healability. Sustainable Energ. Fuels 4 (9), 4713-4721. doi:10.1039/d0se00843e

Eftekhari, A., Li, L., and Yang, Y. (2017). Polyaniline Supercapacitors. J. Power Sourc. 347, 86-107. doi:10.1016/j.jpowsour.2017.02.054

Fan, X., Liu, J., Song, Z., Han, X., Deng, Y., Zhong, C., et al. (2019). Porous Nanocomposite Gel Polymer Electrolyte with High Ionic Conductivity and superior Electrolyte Retention Capability for Long-Cycle-Life Flexible Zinc-Air Batteries. Nano Energy 56, 454-462. doi:10.1016/j.nanoen.2018.11.057

Fang, G., Zhou, J., Pan, A., and Liang, S. (2018). Recent Advances in Aqueous ZincIon Batteries. ACS Energ. Lett. 3 (10), 2480-2501. doi:10.1021/acsenergylett. $8 \mathrm{~b} 01426$

Gaikwad, A. M., Whiting, G. L., Steingart, D. A., and Arias, A. C. (2011). Highly Flexible, Printed Alkaline Batteries Based on Mesh-Embedded Electrodes. Adv. Mater. 23 (29), 3251-3255. doi:10.1002/adma.201100894

Guo, F., Gao, S., Ji, C., Mi, H., Li, H., Zhang, W., et al. (2021). Finely Crafted Polyaniline Cathode for High-Performance Flexible Quasi-Solid-State Zn-Ion Battery. Solid State Ionics 364, 115612. doi:10.1016/j.ssi.2021.115612

Guo, X., Fang, G., Zhang, W., Zhou, J., Shan, L., Wang, L., et al. (2018). Mechanistic Insights of $\mathrm{Zn}^{2+}$ Storage in Sodium Vanadates. Adv. Energ. Mater. 8 (27). doi:10.1002/aenm.201801819

Han, J., Wang, K., Liu, W., Li, C., Sun, X., Zhang, X., et al. (2018). Rational Design of Nano-Architecture Composite Hydrogel Electrode towards High Performance Zn-Ion Hybrid Cell. Nanoscale 10 (27), 13083-13091. doi:10. 1039/c8nr03889a

Han, Q., Chi, X., Zhang, S., Liu, Y., Zhou, B., Yang, J., et al. (2018). Durable, Flexible Self-Standing Hydrogel Electrolytes Enabling High-Safety Rechargeable SolidState Zinc Metal Batteries. J. Mater. Chem. A 6 (45), 23046-23054. doi:10.1039/ c8ta08314b

Hilder, M., Winther-Jensen, B., and Clark, N. B. (2009). Paper-based, Printed Zinc-Air Battery. J. Power Sourc. 194 (2), 1135-1141. doi:10.1016/j.jpowsour. 2009.06.054

Huang, Y., Mou, J., Liu, W., Wang, X., Dong, L., Kang, F., et al. (2019). Novel Insights into Energy Storage Mechanism of Aqueous Rechargeable $\mathrm{Zn} / \mathrm{MnO} 2$ Batteries with Participation of Mn2+. Nano-micro Lett. 11 (1), 49. doi:10.1007/ s40820-019-0278-9

Javed, M. S., Lei, H., Wang, Z., Liu, B-t., Cai, X., and Mai, W. (2020). 2D V $\mathrm{V}_{2} \mathrm{O}_{5}$ Nanosheets as a Binder-free High-Energy Cathode for Ultrafast Aqueous and Flexible Zn-Ion Batteries. Nano Energy 70, 104573. doi:10.1016/j.nanoen.2020. 104573

Jia, Z., Wang, B., and Wang, Y. (2015). Copper Hexacyanoferrate with a WellDefined Open Framework as a Positive Electrode for Aqueous Zinc Ion
Batteries. Mater. Chem. Phys. 149-150, 601-606. doi:10.1016/j.matchemphys. 2014.11.014

Jo, Y. N., Prasanna, K., Kang, S. H., Ilango, P. R., Kim, H. S., Eom, S. W., et al. (2017). The Effects of Mechanical Alloying on the Self-Discharge and Corrosion Behavior in Zn-Air Batteries. J. Ind. Eng. Chem. 53, 247-252. doi:10.1016/j.jiec. 2017.04.032

Kaveevivitchai, W., and Manthiram, A. (2016). High-capacity Zinc-Ion Storage in an Open-Tunnel Oxide for Aqueous and Nonaqueous Zn-Ion Batteries. J. Mater. Chem. A. 4 (48), 18737-18741. doi:10.1039/c6ta07747a

Kumar, R., Johnson, K. M., Williams, N. X., and Subramanian, V. (2019). Scaling Printable $\mathrm{Zn}-\mathrm{Ag}_{2} \mathrm{O}$ Batteries for Integrated Electronics. Adv. Energ. Mater. 9 (13). doi:10.1002/aenm.201803645

Kumar, R., Shin, J., Yin, L., You, J. M., Meng, Y. S., and Wang, J. (2016). AllPrinted, Stretchable $\mathrm{Zn}-\mathrm{Ag}_{2} \mathrm{O}$ Rechargeable Battery via Hyperelastic Binder for Self-Powering Wearable Electronics. Adv. Energ. Mater. 7 (8). doi:10.1002/ aenm.201602096

Lao-atiman, W., Julaphatachote, T., Boonmongkolras, P., and Kheawhom, S. (2017). Printed Transparent Thin Film Zn-MnO2Battery. J. Electrochem. Soc. 164 (4), A859-A863. doi:10.1149/2.1511704jes

Lee, S.-M., Kim, Y.-J., Eom, S.-W., Choi, N.-S., Kim, K.-W., and Cho, S.-B. (2013). Improvement in Self-Discharge of $\mathrm{Zn}$ Anode by Applying Surface Modification for Zn-Air Batteries with High Energy Density. J. Power Sourc. 227, 177-184. doi:10.1016/j.jpowsour.2012.11.046

Li, C., Zhang, Q., Sun, J., Li, T., Songfeng, E., Zhu, Z., et al. (2018). HighPerformance Quasi-Solid-State Flexible Aqueous Rechargeable Ag-Zn Battery Based on Metal-Organic Framework-Derived Ag Nanowires. ACS Energ. Lett. 3 (11), 2761-2768. doi:10.1021/acsenergylett.8b01675

Li, H., Han, C., Huang, Y., Huang, Y., Zhu, M., Pei, Z., et al. (2018). An Extremely Safe and Wearable Solid-State Zinc Ion Battery Based on a Hierarchical Structured Polymer Electrolyte. Energy Environ. Sci. 11 (4), 941-951. doi:10. 1039/c7ee03232c

Li, M., Liu, B., Fan, X., Liu, X., Liu, J., Ding, J., et al. (2019). Long-Shelf-Life Polymer Electrolyte Based on Tetraethylammonium Hydroxide for Flexible Zinc-Air Batteries. ACS Appl. Mater. Inter. 11 (32), 28909-28917. doi:10.1021/acsami. $9 \mathrm{~b} 09086$

Li, R., Li, L., Jia, R., Jiang, K., Shen, G., and Chen, D. (2020). A Flexible Concentric Circle Structured Zinc-Ion Micro-Battery with Electrodeposited Electrodes. Small Methods 4 (9). doi:10.1002/smtd. 202000363

Li, S., Yang, X., Yang, S., Gao, Q., Zhang, S., Yu, X., et al. (2020). An Amorphous Trimetallic (Ni-Co-Fe) Hydroxide-Sheathed 3D Bifunctional Electrode for superior Oxygen Evolution and HighPerformance cable-type Flexible Zinc-Air Batteries. J. Mater. Chem. A 8 (11), 5601-5611. doi:10.1039/d0ta00888e

Li, T., Wang, J., Li, X., Si, L., Zhang, S., and Deng, C. (2020). Unlocking the Door of Boosting Biodirected Structures for High-Performance VNxOy/C by Controlling the Reproduction Mode. Adv. Sci. (Weinh). 7 (5), 1903276. doi:10.1002/advs.201903276

Li, X., Tang, Y., Lv, H., Wang, W., Mo, F., Liang, G., et al. (2019). Recent Advances in Flexible Aqueous Zinc-Based Rechargeable Batteries. Nanoscale 11 (39), 17992-18008. doi:10.1039/c9nr06721c

Li, Y., Fu, J., Zhong, C., Wu, T., Chen, Z., Hu, W., et al. (2018). Recent Advances in Flexible Zinc-Based Rechargeable Batteries. Adv. Energ. Mater. 9 (1). doi:10. 1002/aenm.201802605

Lian, S., Sun, C., Xu, W., Huo, W., Luo, Y., Zhao, K., et al. (2019). Built-in Oriented Electric Field Facilitating Durable Zn MnO2 Battery. Nano Energy 62, 79-84. doi:10.1016/j.nanoen.2019.04.038

Liang, M., Zhou, H., Huang, Q., Hu, S., and Li, W. (2011). Synergistic Effect of Polyethylene Glycol 600 and Polysorbate 20 on Corrosion Inhibition of Zinc Anode in Alkaline Batteries. J. Appl. Electrochem. 41, 991-997. doi:10.1007/ s10800-011-0328-6

Liang, X., Yan, L., Li, W., Bai, Y., Zhu, C., Qiang, Y., et al. (2021). Flexible HighEnergy and Stable Rechargeable Vanadium-Zinc Battery Based on Oxygen Defect Modulated $\mathrm{V}_{2} \mathrm{O}_{5}$ Cathode. Nano Energy 87, 106164. doi:10.1016/j. nanoen.2021.106164

Liao, M., Wang, J., Ye, L., Sun, H., Wen, Y., Wang, C., et al. (2020). A Deep-Cycle Aqueous Zinc-Ion Battery Containing an Oxygen-Deficient Vanadium Oxide 
Cathode. Angew. Chem. Int. Ed. Engl. 59 (6), 2273-2278. doi:10.1002/anie. 201912203

Lin, Y., Zhou, F., Xie, M., Zhang, S., and Deng, C. (2020). $\mathrm{V}_{6} \mathrm{O}_{13}$-delta @C Nanoscrolls with Expanded Distances between Adjacent Shells as a HighPerformance Cathode for a Knittable Zinc-Ion Battery. ChemSusChem 13 (14), 3696-3706. doi:10.1002/cssc.202000699

Liu, J., Guan, C., Zhou, C., Fan, Z., Ke, Q., Zhang, G., et al. (2016). A Flexible QuasiSolid-State Nickel-Zinc Battery with High Energy and Power Densities Based on 3D Electrode Design. Adv. Mater. 28 (39), 8732-8739. doi:10.1002/adma. 201603038

Liu, T., Mou, J., Wu, Z., Lv, C., Huang, J., and Liu, M. (2020). A Facile and Scalable Strategy for Fabrication of Superior Bifunctional Freestanding Air Electrodes for Flexible Zinc-Air Batteries. Adv. Funct. Mater. 30 (36). doi:10.1002/adfm. 202003407

Liu, Y., Xie, L., Zhang, W., Dai, Z., Wei, W., Luo, S., et al. (2019). Conjugated System of PEDOT:PSS-Induced Self-Doped PANI for Flexible Zinc-Ion Batteries with Enhanced Capacity and Cyclability. ACS Appl. Mater. Inter. 11 (34), 30943-30952. doi:10.1021/acsami.9b09802

Liu, Z., Liang, G., Zhan, Y., Li, H., Wang, Z., Ma, L., et al. (2019). A Soft yet DeviceLevel Dynamically Super-tough Supercapacitor Enabled by an EnergyDissipative Dual-Crosslinked Hydrogel Electrolyte. Nano Energy 58, 732-742. doi:10.1016/j.nanoen.2019.01.087

Liu, Z., Mo, F., Li, H., Zhu, M., Wang, Z., Liang, G., et al. (2018). Advances in Flexible and Wearable Energy-Storage Textiles. Small Methods 2 (11). doi:10. 1002/smtd.201800124

Lu, K., Song, B., Zhang, Y., Ma, H., and Zhang, J. (2017). Encapsulation of Zinc Hexacyanoferrate Nanocubes with Manganese Oxide Nanosheets for HighPerformance Rechargeable Zinc Ion Batteries. J. Mater. Chem. A. 5 (45), 23628-23633. doi:10.1039/c7ta07834j

Ma, L., Chen, S., Li, N., Liu, Z., Tang, Z., Zapien, J. A., et al. (2020). Hydrogen-Free and Dendrite-free All-Solid-State Zn-Ion Batteries. Adv. Mater. 32 (14), e1908121. doi:10.1002/adma.201908121

Ma, L., Chen, S., Long, C., Li, X., Zhao, Y., Liu, Z., et al. (2019). Achieving HighVoltage and High-Capacity Aqueous Rechargeable Zinc Ion Battery by Incorporating Two-Species Redox Reaction. Adv. Energ. Mater. 9 (45). doi:10.1002/aenm.201902446

Ma, L., Chen, S., Wang, D., Yang, Q., Mo, F., Liang, G., et al. (2019). SuperStretchable Zinc-Air Batteries Based on an Alkaline-Tolerant Dual-Network Hydrogel Electrolyte. Adv. Energ. Mater. 9 (12). doi:10.1002/aenm.201803046

Ma, L., Chen, S., Li, H., Ruan, Z., Tang, Z., Liu, Z., et al. (2018). Initiating a Mild Aqueous Electrolyte Co3O4/Zn Battery with 2.2 V-High Voltage and 5000cycle Lifespan by a Co(iii) Rich-Electrode. Energ. Environ. Sci. 11 (9), 2521-2530. doi:10.1039/c8ee01415a

Naveed, A., Yang, H., Yang, J., Nuli, Y., and Wang, J. (2019). Highly Reversible and Rechargeable Safe Zn Batteries Based on a Triethyl Phosphate Electrolyte. Angew. Chem. Int. Ed. Engl. 58 (9), 2760-2764. doi:10.1002/ anie. 201813223

Nguyen, T. T., Balamurugan, J., Kim, D. H., Kim, N. H., and Lee, J. H. (2020). Hierarchical 3D Oxygenated Cobalt Vanadium Selenide Nanosheets as Advanced Electrode for Flexible Zinc-Cobalt and Zinc-Air Batteries. Small 16 (48), e2004661. doi:10.1002/smll.202004661

Pan, H., Shao, Y., Yan, P., Cheng, Y., Han, K. S., Nie, Z., et al. (2016). Reversible Aqueous Zinc/manganese Oxide Energy Storage from Conversion Reactions. Nat. Energ. 1, 16039. doi:10.1038/nenergy.2016.39

Pang, Y., Cao, Y., Chu, Y., Liu, M., Snyder, K., Mackenzie, D., et al. (2019). Additive Manufacturing of Batteries. Adv. Funct. Mater. 30 (1). doi:10.1002/adfm. 201906244

Qiu, W., Li, Y., You, A., Zhang, Z., Li, G., Lu, X., et al. (2017). High-performance Flexible Quasi-Solid-State Zn-MnO2 Battery Based on MnO2 Nanorod Arrays Coated 3D Porous Nitrogen-Doped Carbon Cloth. J. Mater. Chem. A. 5 (28), 14838-14846. doi:10.1039/c7ta03274a

Shi, H.-Y., Ye, Y.-J., Liu, K., Song, Y., and Sun, X. (2018). A Long-Cycle-Life SelfDoped Polyaniline Cathode for Rechargeable Aqueous Zinc Batteries. Angew. Chem. Int. Ed. 57 (50), 16359-16363. doi:10.1002/anie.201808886

Song, H., Liu, C., Zhang, C., and Cao, G. (2016). Self-doped $\mathrm{V}^{4+}-\mathrm{V}_{2} \mathrm{O}_{5}$ Nanoflake for $2 \mathrm{Li}$-Ion Intercalation with Enhanced Rate and Cycling Performance. Nano Energy 22, 1-10. doi:10.1016/j.nanoen.2016.02.004
Song, M., Tan, H., Chao, D., and Fan, H. J. (2018). Recent Advances in Zn-Ion Batteries. Adv. Funct. Mater. 28 (41). doi:10.1002/adfm.201802564

Sumboja, A., Liu, J., Zheng, W. G., Zong, Y., Zhang, H., and Liu, Z. (2018). Electrochemical Energy Storage Devices for Wearable Technology: a Rationale for Materials Selection and Cell Design. Chem. Soc. Rev. 3047 (15), 5919-5945. doi: $10.1039 / \mathrm{c} 8 \mathrm{cs} 00237 \mathrm{a}$

Tan, P., Chen, B., Xu, H., Cai, W., He, W., Zhang, H., et al. (2018). Integration of Zn-Ag and Zn-Air Batteries: A Hybrid Battery with the Advantages of Both. ACS Appl. Mater. Inter. 10 (43), 36873-36881. doi:10.1021/acsami.8b10778

Tan, P., Chen, B., Xu, H., Zhang, H., Cai, W., Ni, M., et al. (2017). Flexible Zn- and Li-Air Batteries: Recent Advances, Challenges, and Future Perspectives. Energ. Environ. Sci. 10 (10), 2056-2080. doi:10.1039/c7ee01913k

Tang, B., Shan, L., Liang, S., and Zhou, J. (2019). Issues and Opportunities Facing Aqueous Zinc-Ion Batteries. Energ. Environ. Sci. 12 (11), 3288-3304. doi:10. $1039 / \mathrm{c} 9 \mathrm{ee} 02526 \mathrm{j}$

Tehrani, Z., Korochkina, T., Govindarajan, S., Thomas, D. J., Mahony, J. O., Kettle, J., et al. (2015). Ultra-thin Flexible Screen Printed Rechargeable Polymer Battery for Wearable Electronic Applications. Org. Electronics 26, 386-394. doi:10.1016/j.orgel.2015.08.007

vKundu, D., Adams, B. D., Duffort, V., Vajargah, S. H., and Nazar, L. F. (2016). A High-Capacity and Long-Life Aqueous Rechargeable Zinc Battery Using a Metal Oxide Intercalation Cathode. Nat. Energ. 1 (10). doi:10.1038/nenergy. 2016.119

Wan, F., Zhang, L., Dai, X., Wang, X., Niu, Z., and Chen, J. (2018). Aqueous Rechargeable Zinc/sodium Vanadate Batteries with Enhanced Performance from Simultaneous Insertion of Dual Carriers. Nat. Commun. 9 (1), 1656. doi:10.1038/s41467-018-04060-8

Wang, D., Li, H., Liu, Z., Tang, Z., Liang, G., Mo, F., et al. (2018). A Nanofibrillated Cellulose/Polyacrylamide Electrolyte-Based Flexible and Sewable HighPerformance $\mathrm{Zn}-\mathrm{MnO}_{2}$ Battery with Superior Shear Resistance. Small 14 (51), e1803978. doi:10.1002/smll.201803978

Wang, H., Bi, X., Bai, Y., Wu, C., Gu, S., Chen, S., et al. (2017). Open-Structured $\mathrm{V}_{2} \mathrm{O}_{5} \cdot \mathrm{nH}_{2} \mathrm{O}$ Nanoflakes as Highly Reversible Cathode Material for Monovalent and Multivalent Intercalation Batteries. Adv. Energ. Mater. 7 (14). doi:10.1002/ aenm.201770077

Wang, X., Zheng, S., Zhou, F., Qin, J., Shi, X., Wang, X., et al. (2020). Scalable Fabrication of Printed $\mathrm{Zn} / / \mathrm{MnO}_{2}$ Planar Micro-batteries with High Volumetric Energy Density and Exceptional Safety. Natl. Sci. Rev. 7 (1), 64-72. doi:10.1093/ nsr/nwz070

Wang, Z., Meng, X., Chen, K., and Mitra, S. (2018). Synthesis of Carbon Nanotube Incorporated Metal Oxides for the Fabrication of Printable, Flexible NickelZinc Batteries. Adv. Mater. Inter. 5 (4). doi:10.1002/admi.201701036

Xu, C., Li, B., Du, H., and Kang, F. (2012). Energetic Zinc Ion Chemistry: the Rechargeable Zinc Ion Battery. Angew. Chem. Int. Ed. 51 (4), 933-935. doi:10. 1002/anie.201106307

Xu, W., Sun, C., Wang, N., Liao, X., Zhao, K., Yao, G., et al. (2021). Sn Stabilized Pyrovanadate Structure Rearrangement for Zinc Ion Battery. Nano Energy 81, 105584. doi:10.1016/j.nanoen.2020.105584

Xu, Y., Zheng, S., Tang, H., Guo, X., Xue, H., and Pang, H. (2017). Prussian Blue and its Derivatives as Electrode Materials for Electrochemical Energy Storage. Energ. Storage Mater. 9, 11-30. doi:10.1016/j.ensm.2017.06.002

Yan, K., Li, J., Pan, L., and Shi, Y. (2020). Inkjet Printing for Flexible and Wearable Electronics. APL Mater. 8 (12). doi:10.1063/5.0031669

Yao, H., Li, Q., Zhang, M., Tao, Z., and Yang, Y. (2020). Prolonging the Cycle Life of Zinc-Ion Battery by Introduction of $\left[\mathrm{Fe}(\mathrm{CN})_{6}\right]^{4-}$ to PANI via a Simple and Scalable Synthetic Method. Chem. Eng. J. 392, 123653. doi:10.1016/j.cej.2019. 123653

Yin, L., Scharf, J., Ma, J., Doux, J.-M., Redquest, C., Le, V. L., et al. (2021). High Performance Printed AgO-Zn Rechargeable Battery for Flexible Electronics. Joule 5, 228-248. doi:10.1016/j.joule.2020.11.008

Yu, M., Lin, D., Feng, H., Zeng, Y., Tong, Y., and Lu, X. (2017). Boosting the Energy Density of Carbon-Based Aqueous Supercapacitors by Optimizing the Surface Charge. Angew. Chem. Int. Ed. 56 (20), 5454-5459. doi:10.1002/anie.201701737

Yu, M., Zeng, Y., Han, Y., Chen, X., Zhao, W., Liang, C., et al. (2015). Valenceoptimized Vanadium Oxide Supercapacitor Electrodes Exhibit Ultrahigh Capacitance and Super-long Cyclic Durability of 100000 Cycles. Adv. Funct. Mater. 25, 3534-3540. doi:10.1002/adfm.201501342 
Yu, P., Zeng, Y., Zhang, H., Yu, M., Tong, Y., and Lu, X. (2019). Flexible Zn-Ion Batteries: Recent Progresses and Challenges. Small 15 (7), e1804760. doi:10. 1002/smll.201804760

Yza, B., Gl, A., and Cz, A. (2022). Low-cost MgFe X Mn ${ }_{2-\mathrm{x}} \mathrm{O}_{4}$ Cathode Materials for High-Performance Aqueous Rechargeable Magnesium-Ion Batteries. Chem. Eng. J. 392.

Zeng, Y., Zhang, X., Qin, R., Liu, X., Fang, P., Zheng, D., et al. (2019). Dendrite-Free Zinc Deposition Induced by Multifunctional CNT Frameworks for Stable Flexible Zn-Ion Batteries. Adv. Mater. 31 (36), e1903675. doi:10.1002/adma. 201903675

Zhang, J., Li, X. L., Fan, S., Huang, S., Yan, D., Liu, L., et al. (2020). 3D-printed Functional Electrodes towards Zn-Air Batteries. Mater. Today Energ. 16. doi:10. 1016/j.mtener.2020.100407

Zhang, L., Chao, D., and Yang, P. (2020). Flexible Pseudocapacitive Electrochromics via Inkjet Printing of Additive-Free Tungsten Oxide Nanocrystal Ink. Adv. Energ. Mater. 10 (17). doi:10.1002/aenm.202000142

Zhang, L., Chen, L., Zhou, X., and Liu, Z. (2015). Towards High-Voltage Aqueous Metal-Ion Batteries beyond 1.5 V: The Zinc/Zinc Hexacyanoferrate System. Adv. Energ. Mater. 5 (2). doi:10.1002/aenm.201400930

Zhang, N., Cheng, F., Liu, J., Wang, L., Long, X., Liu, X., et al. (2017). Rechargeable Aqueous Zinc-Manganese Dioxide Batteries with High Energy and Power Densities. Nat. Commun. 8 (1), 405. doi:10.1038/s41467-017-00467-x

Zhang, N., Cheng, F., Liu, Y., Zhao, Q., Lei, K., Chen, C., et al. (2016). CationDeficient Spinel ZnMn2O4 Cathode in $\mathrm{Zn}(\mathrm{CF} 3 \mathrm{SO} 3) 2$ Electrolyte for Rechargeable Aqueous Zn-Ion Battery. J. Am. Chem. Soc. 138 (39), 12894-12901. doi:10.1021/jacs.6b05958

Zhang, W., Zuo, C., Tang, C., Tang, W., Lan, B., Fu, X., et al. (2020). The Current Developments and Perspectives of $\mathrm{V}_{2} \mathrm{O}_{5}$ as Cathode for Rechargeable Aqueous Zinc-Ion Batteries. Energ. Technology 9 (2). doi:10.1002/ente.202000789

Zhang, Y., Deng, S., Pan, G., Zhang, H., Liu, B., Wang, X. L., et al. (2020). Introducing Oxygen Defects into Phosphate Ions Intercalated Manganese Dioxide/Vertical Multilayer Graphene Arrays to Boost Flexible Zinc Ion Storage. Small Methods 4 (6). doi:10.1002/smtd.201900828

Zhang, Y., Tao, L., Xie, C., Wang, D., Zou, Y., Chen, R., et al. (2020). Defect Engineering on Electrode Materials for Rechargeable Batteries. Adv. Mater. 32 (7), e1905923. doi:10.1002/adma.201905923
Zhang, Y., Xu, G., Liu, X., Wei, X., Cao, J., and Yang, L. (2020). Scalable In Situ Reactive Assembly of Polypyrrole-Coated MnO 2 Nanowire and Carbon Nanotube Composite as Freestanding Cathodes for High Performance Aqueous Zn-Ion Batteries. ChemElectroChem 7 (13), 2762-2770. doi:10. 1002/celc. 202000253

Zhang, Z., Cui, L., Shi, X., Tian, X., Wang, D., Gu, C., et al. (2018). Textile Display for Electronic and Brain-Interfaced Communications. Adv. Mater. 30 (18), e1800323. doi:10.1002/adma.201800323

Zhao, J., Sonigara, K. K., Li, J., Zhang, J., Chen, B., Zhang, J., et al. (2017). A Smart Flexible Zinc Battery with Cooling Recovery Ability. Angew. Chem. Int. Ed. Engl. 56, 7871-7875. doi:10.1002/anie.201704373

Zhao, J., Ren, H., Liang, Q., Yuan, D., Xi, S., Wu, C., et al. (2019). Highperformance Flexible Quasi-Solid-State Zinc-Ion Batteries with LayerExpanded Vanadium Oxide Cathode and Zinc/stainless Steel Mesh Composite Anode. Nano Energy 62, 94-102. doi:10.1016/j.nanoen.2019.05.010

Zu, D., Wang, H., Lin, S., Ou, G., Wei, H., Sun, S., et al. (2019). Oxygen-deficient Metal Oxides: Synthesis Routes and Applications in Energy and Environment. Nano Res. 12 (9), 2150-2163. doi:10.1007/s12274-019-2377-9

Conflict of Interest: The authors declare that the research was conducted in the absence of any commercial or financial relationships that could be construed as a potential conflict of interest.

Publisher's Note: All claims expressed in this article are solely those of the authors and do not necessarily represent those of their affiliated organizations, or those of the publisher, the editors and the reviewers. Any product that may be evaluated in this article, or claim that may be made by its manufacturer, is not guaranteed or endorsed by the publisher.

Copyright (c) $2022 \mathrm{Xu}, \mathrm{Xu}$, Guo, Zhang and Wang. This is an open-access article distributed under the terms of the Creative Commons Attribution License (CC BY). The use, distribution or reproduction in other forums is permitted, provided the original author(s) and the copyright owner(s) are credited and that the original publication in this journal is cited, in accordance with accepted academic practice. No use, distribution or reproduction is permitted which does not comply with these terms. 